\title{
INFLUÊNCIA DE SISTEMAS DE CULTIVO NA PRODUÇÃO DE MUDAS DE QUATRO ESPÉCIES AROMÁTICAS E MEDICINAIS
}

\author{
PATRÍCIA DE LYRA LINO
}

Engenheiro Agrônomo

Orientador: Prof. Dr. KEIGO MINAMI

Dissertação apresentada à Escola Superior de Agricultura "Luiz de Queiroz", Universidade de São Paulo, para obtenção do título de Mestre em Agronomia, Área de Concentração: Fitotecnia.

PIRACICABA

Estado de São Paulo - Brasil

Dezembro - 2004 
Dados Internacionais de Catalogação na Publicação (CIP) DIVISĀO DE BIBLIOTECAE DOCUMENTAÇĀO -ESALQ/USP

Lino, Patrícia de Lyra

Influência de sistemas de cultivo na produção de mudas de quatro espécies aromáticas e medicinais / Patricia de Lyra Lino. - - Piracicaba, 2004

$59 \mathrm{p}$.

Dissertação (Mestrado) - - Escola Superior de Agricultura Luiz de Queiroz, 2004.

Bibliografia.

1. Alecrim 2. Balsamo 3. Carqueja 4. Estaca 5. Planta aromática 6. Planta medicinal 7. Sistema de cultivo 8 . Sistema dinâmico 9 . Tomilho I. Título

$\operatorname{CDD} 633.8$

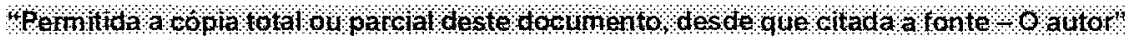


Ao Meu Grande Amor CRISTIANO VOLL, pelo modelo de sabedoria, paciência, dedicação

e amor, que me impulsionou

e me fez sempre perseverar ...

Dedico

Este trabalho é dedicado a minha mãe IRACEMA DE LYRA e aos meus avós JOSÉ MONTEIRO DE LIRA e MARIA DE LOURDES C. DE LIRA que sempre me deram muito amor, carinho, força, estímulo e coragem em todas as minhas realizações. São pessoas muito especiais e essenciais na minha vida e que eu amo muito. Obrigada por acreditarem em mim.

Ofereço 


\section{AGRADECIMENTOS}

Ao CNPq (Conselho Nacional de Pesquisa e Desenvolvimento), pelo suporte financeiro e pela bolsa de estudo, sem a qual não haveria a possibilidade de realização deste trabalho.

À Prof Dr. Luciane Vilela da Universidade Federal Rural de Pernambuco, pelo incentivo ao mestrado, apoio e amizade.

Ao Prof. Dr. Keigo Minami, principalmente pela dedicada orientação, e também pela amizade e confiança durante o mestrado.

Ao Prof. Dr. Roque Dechen e FEALQ, pela amizade e apoio financeiro em muitos eventos científicos.

Ao Prof. Dr. Lindolpho Capellari Junior, pela correção da dissertação e amizade.

A Luciane Aparecida Lopes, secretária da Pós-Graduação do Departamento de Produção Vegetal, pela paciência, conselhos, atenção dedicada e amizade.

Ao Prof Dr. Carlos Tadeu pela colaboração na definição dos delineamentos experimentais utilizados.

Ao meu padastro Elton, pela amizade, carinho, atenção e importantíssima participação durante o mestrado.

Ao meu Cris, pela atenção, dedicação, carinho, amor, apoio e participação nos últimos tempos. 
As bibliotecárias Eliana Maria Garcia Sabino e Kátia M. de Andrade Ferraz, da biblioteca central da Escola Superior de Agricultura "Luiz de Queiroz".

Aos Srs. Aparecido, Galdêncio, Ereinaldo, Zé, Carlinhos, Rogério e Gerson, funcionários da Horta do Departamento de Produção Vegetal da ESALQ, sempre prestativos durante os serviços solicitados na instalação e manutenção da área experimental.

À Krak, Eduardo, Juan e Leticia Alfin (Química de Solos), pelo convívio, participação e apoio nas atividades inclusive nas braçais.

Aos meus grandes amigos Valdomiro e Vanessa Benez, pela amizade, dedicação, atenção e convívio.

Aos amigos Ariana, Tathyana Cambri, Michel Cambri, Eros, In off, Jack Fernando, Gilmar e Heliane Nachtigall, Xavier e Ivone, Aline, Chiclete, Ricardo, Guy, Fernando Oliveira, Kercya, Hector (Animal), Raline, Edna e Tony, Fabio Aquino e Gisele, Gambé e Eliane, Prof. Dr. Cyro P. Costa, Prof. Dr. Paulo Cesar Tavares e todos que fazem a academia Autopira.

As grandes amigas de Recife Maria Lucia Montanha e Maria Helena Monteiro.

A minha irmã Nancy, pela amizade, dedicação e principalmente pela atenção.

Finalmente, a TODOS que direta ou indiretamente auxiliaram este trabalho, meus sinceros agradecimentos. 


\section{SUMÁRIO}

Página

LISTA DE TABELAS ................................................................... viii

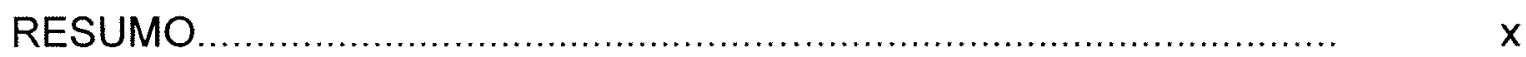

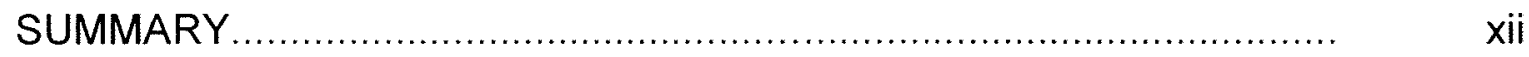

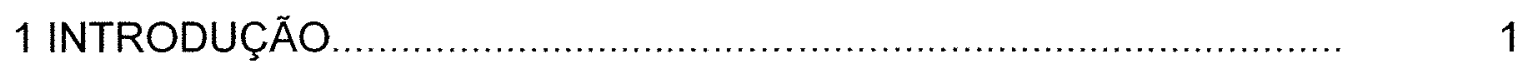

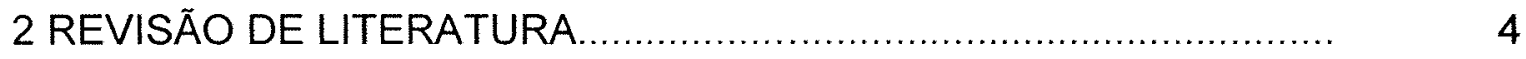

2.1 Considerações gerais das espécies...............................................

2.1.1 Aspectos gerais do Alecrim (Rosmarinus officinalis L.)................. 5

2.1.2 Aspectos gerais do Bálsamo (Sedum dendroideum subsp. praealtum (DC.) R.T. Clausen) ........................................................... 8

2.1.3 Aspectos gerais do Carqueja (Baccharis trimera (Less.) 10

D.C.)

2.1.4 Aspectos gerais do Tomilho (Thymus vulgaris

L.).

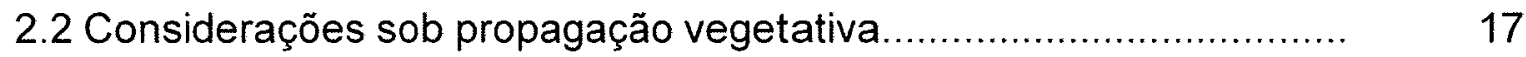

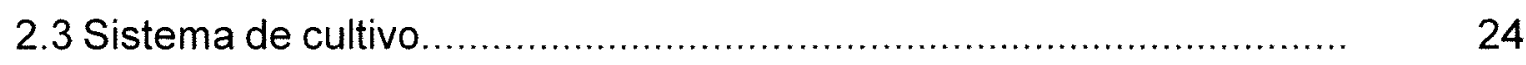

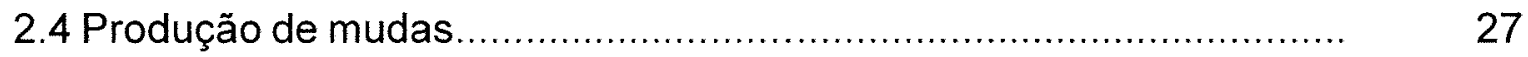

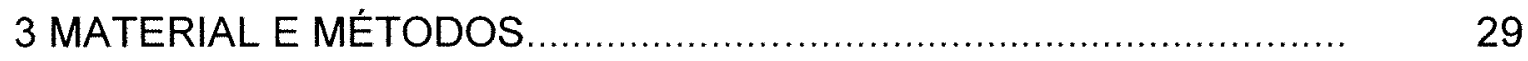

3.1 Local de realização do experimento............................................. 29

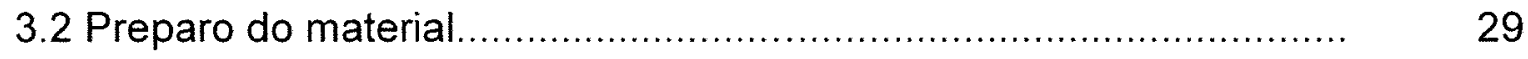

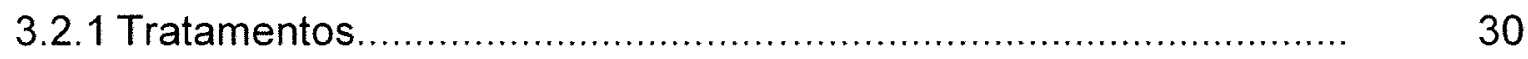

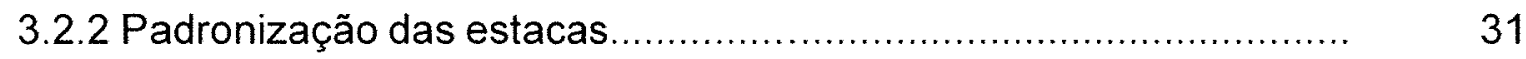




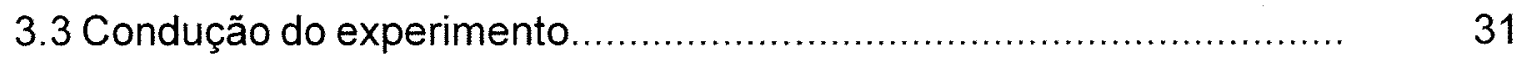

3.4 Delineamento experimental....................................................... 31

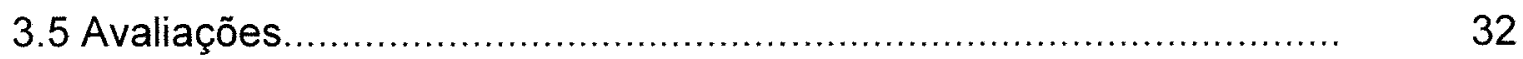

3.5.1 Qualidade de enraizamento.................................................... 32

3.5.2 Peso de massa fresca da parte aérea e raiz ................................ 32

3.5.3 Peso de massa seca da parte aérea e raiz .................................. 32

4 RESULTADOS E DISCUSSÃO....................................................... 33

4.1 Avaliação da produção de mudas do Alecrim ................................... 33

4.2 Avaliação da produção de mudas do Bálsamo................................... 35

4.3 Avaliação da produção de mudas do Carqueja................................ 36

4.4 Avaliação da produção de mudas do Tomilho.................................... 40

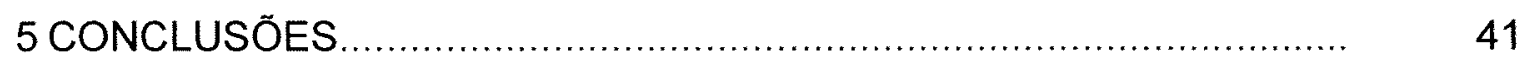

REFERÊNCIAS BIBLIOGRÁFICAS ............................................... 42 


\section{LISTA DE TABELAS}

Página

1 Tipos de propagação de mudas para cada espécie............................. 30

2 Médias dos parâmetros para o alecrim (Rosmarinus officinalis L.) para qualidade do enraizamento (QE), peso de massa verde de parte aérea (PVPA), peso de massa verde de raiz (PVR) avaliadas no verão e inverno.

3 Médias dos parâmetros para o alecrim (Rosmarinus officinalis L.) para qualidade do enraizamento (QE), peso de massa verde da raiz (PVR) avaliados para os dois tipos de estacas

4 Peso de massa verde de raiz (PVR) do alecrim (Rosmarinus officinalis L.) avaliados para os sistemas de cultivo

5 Peso de massa verde de raiz (PVR) e qualidade do enraizamento (QE) do bálsamo (Sedum dendroideum subsp. praealtum (DC.) R.T. Clausen) avaliados para os sistemas de cultivo no inverno.......

6 Peso de massa verde de parte aérea (PVPA) e peso de massa seca de parte aérea (PSPA), da carqueja (Baccharis trimera (Less.) D.C.) avaliados para os sistemas de cultivo no inverno.........

7 Qualidade do enraizamento (QE) da carqueja (Baccharis trimera (Less.) D.C.) avaliadas sob o tipo da estaca no inverno. 
8 Médias da interação sistema $x$ tipo de estaca, avaliadas para peso de massa verde de raiz (PVR) nas mudas de carqueja (Baccharis trimera (Less.) D.C.)

9 Peso de massa verde de parte aérea (PVPA) e qualidade do enraizamento ( $Q E)$ da carqueja (Baccharis trimera (Less.) D.C.) avaliadas no verão e inverno.

10 Médias da interação sistema $\mathrm{x}$ época do ano, avaliadas para peso de massa verde de raiz (PVR) nas mudas de carqueja (Baccharis trimera (Less.) D.C.)

11 Peso de massa verde de parte aérea (PVPA) e peso de massa seca de parte aérea (PSPA), peso de massa verde de raiz (PVR), peso de massa seca de raiz (PSR) do tomilho (Thymus vulgaris $L$.) avaliados para os sistemas de cultivo no inverno 


\title{
INFLUÊNCIA DE SISTEMAS DE CULTIVO NA PRODUÇÃO DE MUDAS DE QUATRO ESPÉCIES AROMÁTICAS E MEDICINAIS
}

\author{
Autora: PATRÍCIA DE LYRA LINO
} Orientador: Prof. Dr. KEIGO MINAMI

RESUMO

Considerando as tendências vigentes e as dificuldades para garantir a qualidade e a estabilidade dos medicamentos fitoterápicos, objetivou-se neste trabalho estudar a produção de mudas de alta qualidade de alecrim (Rosmarinus officinalis L.); bálsamo (Sedum dendroideum subsp. Praealtum (DC.) R.T. Clausen); carqueja (Baccharis trimera (Less.) D.C.) e, tomilho (Thymus vulgaris L.), bem como realizar um estudo comparativo das estruturas vegetativas dessas espécies em casa-de-vegetação com a época do ano. Os experimentos foram conduzidos na área experimental do Departamento de Produção Vegetal da Escola Superior de Agricultura "Luiz de Queiroz" da Universidade de São Paulo, em Piracicaba. Foram utilizados três tratamentos com quatro repetições, procurando-se avaliar tanto o enraizamento como, os segmentos dos ramos que melhor produzem mudas de qualidade. Os tratamentos foram assim denominados: A -Testemunha, sistema convencional (bandeja de poliestireno expandido de 128 células preenchidas com plantmax HT e mantidas sob casa de vegetação com irrigação intermitente); B - Sistema "floating" (bandeja de poliestireno expandido de 128 células preenchidas com plantmax HT e mantidas em "piscina" contendo apenas água, onde ficaram 
flutuando por todo periodo de desenvolvimento das mudas); C - Sistema de bandejas plásticas preenchidas com areia lavada (mantidas sob casa de vegetação com irrigação intermitente). $A$ análise dos resultados revelou que as mudas formadas pelas estacas apicais de alecrim, carqueja e tomilho apresentaram as maiores médias para os parâmetros estudados. A utilização do sistema "floating" no condicionamento e desenvolvimento de mudas de carqueja formadas por estacas apicais, no verão, apresentaram ser viável, permitindo o controle do desenvolvimento das mesmas e proporcionando melhores índices de pegamento em campo. Plantas de bálsamo produzem mudas de alta qualidade no inverno, quando plantadas no sistema de areia. As maiores produções de mudas de tomilho foram obtidas no inverno, utilizando o sistema convencional.

Palavra-Chaves: Floating, sistemas de cultivo, tipos de estacas alecrim, balsamo, carqueja, tomilho. 


\title{
INFLUENCE OF CROP SYSTEMS IN SEEDLING PRODUCTION OF FOUR AROMATICS AND MEDICINAL SPECIES
}

\author{
Author: PATRÍCIA DE LYRA LINO \\ Adviser: Prof. Dr. KEIGO MINAMI
}

\author{
SUMMARY
}

Considering the actual tendencies and the difficulties to insure quality and stability of medicinal plants, this work had as an objective to study the seedling production of high quality of four aromatic and medicinal species: rosemary (Rosmarinus officinalis L.); balsam (Sedum dendroideum subsp. Praealtum (DC.) R.T. Clausen); carqueja (Baccharis trimera (Less.) D.C.) and, thyme (Thymus vulgaris $L$ ). Furthermore it proposed to make a comparative study with the vegetative structure of these species in a greenhouse in two different time of the year. The experiments were conducted in the experimental area of the Plant Production Department of the Escola Superior de Agricultura "Luiz de Queiroz", USP, in Piracicaba. It was used three treatments with for replications in a complete randomized design to evaluate root production and the part of stem which give the best quality seedlings. The treatments were $A$ - control, traditional system (polystyrene tray expanded to 128 cells filled with plantmax HT and maintained in a greenhouse under intermittent irrigation); B - floating system (polystyrene tray expanded to 128 cells filled with plantmax HT and maintained in a pool with just water floating for all experimental period); $\mathrm{C}$ - plastic tray 
system filled with washed sand (maintained under greenhouse conditions with intermittent irrigation). The analysis of the data showed that the seedlings originated from apical stem of rosemary, carqueja and thyme had the best average production for the parameters studied. The utilization of the floating system in the conditioning and development of carqueja seedlings obtained from apical cuttings in summer time were experimentally viable allowing seedling development had and propitiating the best field rooting. B Balsam plants produce high quality seedlings in the winter when planted in the sand system. The best production of thyme seedling was obtained in the winter using the traditional system.

Key words: floating, crop systems, stem cuttings, rosemary, carqueja, balsam, thyme 


\section{INTRODUÇÃO}

A utilização de plantas como fonte de medicamentos, para o tratamento das enfermidades que acometem a espécie humana, remonta à idade antiga ou ainda aos primórdios da civilização. Certamente, a terapêutica moderna composta por um grande número de medicamentos, não teria atingido o grau de desenvolvimento atual se não fosse o auxilio dos produtos naturais, notadamente aquele derivado das plantas superiores (Calixto, 2001). No Brasil, a medicina popular teve a influência da colonização portuguesa, que trouxe uma imensa contribuição colhida no gigantesco império colonial português (Figueiredo, 1979) dos imigrantes, dos indígenas nativos, que usavam a fitoterapia dentro da visão mística; e, por último, dos escravos negros africanos, com a medicina mágica (Campelo, 1988).

O Brasil, reconhecidamente, é o pais detentor de uma das mais altas taxas de biodiversidade. O potencial de obtenção de novos medicamentos é grande em relação ao número de espécies, sendo que esta fonte tão vasta de recursos não passou despercebida pela humanidade, e tem despertado interesses de diversas nações sobre nossa imensa flora vegetal.

A fitoterapia foi largamente utilizada até meados do século $X X$. Com a evolução da química e dos processos tecnológicos, os produtos naturais foram sendo substituídos por produtos sintéticos (Sá, 1992).

A falta de conhecimento e informação sobre essas plantas potenciais, pode ser constatada a partir das bases primárias de suas atividades, pois estão em estágio inicial até mesmo as pesquisas agronômicas voltadas ao cultivo das espécies mais comuns (Furlan, 1996). Estes dificuldades estão começando a serem resolvidas por meio de pesquisas agronômicas, que oferecem subsídios 
para o cultivo das espécies em campo a céu aberto ou como cultura convencional. Algumas pesquisas mostram que mesmo variações genéticas dentro de uma espécie podem alterar o teor do princípio ativo (Di Stasi, 1996).

Segundo Calixto (2001), o aspecto mais crítico na produção dos medicamentos fitoterápicos é, sem dúvida, a qualidade da matéria-prima vegetal. Para evitar tais problemas, e visando manter o máximo possível a estabilidade e a qualidade dos medicamentos fitoterápicos, as indústrias estão procurando melhorias, através do cultivo de plantas medicinais em larga escala. Além de poder eliminar as variações, tais como clima, nutrientes e luminosidade, o cultivo em larga escala permite selecionar espécies com maior teor de princípios ativos, controlar pragas ou ainda, o que é fundamental, evitar contaminações por metais pesados, inseticidas e outros fatores que afetam diretamente a qualidade, a segurança e a eficácia clínica dos medicamentos fitoterápicos.

Dos medicamentos disponíveis, $25 \%$ são originários de princípios ativos extraídos de vegetais. Nesse campo, o Brasil leva uma vantagem considerável. Segundo Yunes et al. (2001), das 350 mil espécies existentes no mundo, pelo menos 140 mil são tipicamente brasileiras. A pesquisa com fitoterápicos é a única chance de o Brasil competir no concorrido mercado mundial de desenvolvido tecnológico, patenteando internacionalmente os extratos (Sertié, 1997).

Assim, as plantas medicinais passaram novamente a serem consideradas recurso terapêutico viável. Estimativas da Organização Mundial da Saúde (OMS) relatam que cerca de $80 \%$ da população dos países em desenvolvimento fazem uso de algum tipo de medicina tradicional para cuidados básicos de saúde e $85 \%$ deste envolvem o uso de plantas (Clemente Filha, 1996; Castro, 2003). Por esta razão, recomendaram-se aos países membros que desenvolvessem pesquisas visando a utilização da flora nacional com propósito terapêutico. Em 1981, o Ministério da Saúde do Brasil baixou as "Diretrizes e Propriedades de Investigação em Saúde", onde está incluído o 
estudo das plantas medicinais (Scheffer, 1991). Esta resolução condiciona o uso das plantas medicinais ao estudo aprofundado do ponto de vista taxonômico, fisiológico, fitotécnico, antropológico, químico e farmacológico, abrindo um campo de trabalho de alta relevância no Brasil, embora incipiente (Becker, 1997).

Outra grande relevância das plantas medicinais é citada por Fidelis (1998) onde as indústrias de alimentos as utilizam para restaurar o aroma, a cor e o pigmento dos alimentos processados, agentes de condimentos, corantes, etc. O mercado de condimentos em 1987 foi estimado na ordem de US $\$ 1,8$ bilhões e de fragrância em US $\$ 1,9$ milhões (Pearce, 1988).

As plantas aromáticas, que além de produtoras de óleos voláteis ou essenciais, são também medicinais, estão presentes no cotidiano das pessoas. Estas plantas ou as substâncias voláteis delas extraidas, têm sido usadas para conferir ou modificar sabor em alguns alimentos; como medicamentos ou parte integrante deles, na cura de doenças (aromaterapia, antissépticos, analgésicos etc), na composição de perfumes e em incensos para práticas religiosas (Martins, 1996).

Considerando as tendências vigentes e as dificuldades para garantir a qualidade e a estabilidade dos medicamentos fitoterápicos, objetivou-se neste trabalho estudar a produção de mudas de alta qualidade de alecrim (Rosmarinus officinalis L.); bálsamo (Sedum dendroideum subsp. Praealtum (DC.) R.T. Clausen); carqueja (Baccharis trimera (Less.) D.C.) e, tomilho (Thymus vulgaris L.), bem como realizar um estudo comparativo das estruturas vegetativas dessas espécies em casa-de-vegetação com a época do ano. 


\section{REVISÃO DE LITERATURA}

\subsection{Considerações gerais das espécies}

Atualmente tem se observado uma nova tendência quanto ao uso de plantas medicinais que estão cada vez mais difundidas, não só no Brasil, como também em outros paises, especialmente na Europa. Grande parte da população não sabe como reconhecê-las; não tendo noção do que estão adquirindo, o que as induzem a serem enganadas pelos comerciantes.

Tetenyi (1991) comenta que em plantas medicinais, a produção de metabólitos secundários está sujeita à variação de fatores exógenos e endógenos. Portanto, no cultivo de espécies medicinais, devem-se levar em conta fatores genéticos, fisiológicos e ecológicos que influenciam a produção de fármacos.

Para Elysabetsky (1986) as pontencialidades do uso das plantas medicinais podem ser avaliadas com base no exemplo da China. Este país mantém 400.000 hectares cultivados com plantas medicinais, permitindo a existência de 800 indústrias farmacêuticas nacionais. Elas empregam 80.000 trabalhadores, produzindo cerca de 2.000 tipos de medicamentos. Essa cifra eleva-se para 220.000 pessoas quando se consideram aquelas envolvidas com plantio, processamento e distribuição de plantas medicinais.

Scheffer (1991) comenta que são poucas as informações disponiveis do ponto de vista agronômico, evidenciando-se, assim, a necessidade da realização de estudos que revelem o comportamento destas espécies quando 
submetidas às técnicas de produção agrícola. Estas devem atender ao duplo objetivo, qual seja o de aumentar a produção de biomassa/área, sem comprometer o valor terapêutico da planta. As variações nas concentrações de substâncias ativas das plantas ocorrem em função das condições edafoclimáticas, da idade na época da coleta, e da sanidade que devem ser observadas, visando o controle de qualidade dos fitofármacos.

\subsubsection{Aspectos Gerais do Alecrim (Rosmarinus officinalis L.)}

De acordo com a classificação de Cronquist (1981), o alecrim ocupa a seguinte posição taxonômica:

Divisão: Magnoliophyta

Classe: Magnoliopsida

Subclasse: Asteridae

Ordem: Lamiales

Familia: Lamiaceae

Gênero: Rosmarinus

Espécie: Rosmarinus officinalis L.

A familia constituída por cerca de 200 gêneros e 3.200 espécies, cosmopolitas, é abundante na região do Mediterrâneo e no leste da Ásia Central; com mais da metade das espécies pertencentes somente a 8 gêneros (Cronquist, 1981).

O alecrim (Rosmarinus officinalis L.) é um subarbusto ramificado originário da região mediterrânea, que possui folhas sésseis, opostas, lineares, com as bordas voltadas para baixo, verde-escuras na face superior e esbranquiçada na inferior. As suas flores são diminutas, bilabiadas e em cimeras. O fruto consiste de quatro aquênios obovais. Toda a planta exala 
cheiro aromático agradável (Peckolt \& Peckolt ${ }^{1}$, citado por Vieira, 1992; Balbach, s.d., Von Hertwig, 1986; Corrêa Jr. et al., 1994; Silva, 1998).

Segundo Magalhães, (1997) e Cardamone, (1999), o alecrim é uma espécie perene de porte arbustivo ramificado, cresce até $1,50 \mathrm{~m}$ de altura, o caule é lenhoso e folhoso. As folhas são sésseis, coriáceas, estreitas, com bordos enrolados e persistentes, e as flores são desde azul-claro a esbranquiçada, em pequenos cachos axilares, cálices curto campanulado, com 3 dentes; corola longa, com 2 lábios, um com 2 lóbulos eretos e o outro com 3 lóbulos, sendo o médio maior e côncavo, 2 estames. A planta apresenta aroma muito forte e floresce o ano todo. É uma planta de clima quente, com dias longos e luminosos, sendo também usada como planta ornamental, principalmente nos Estados Unidos, onde é comum encontrá-la nos canteiros centrais das avenidas, jardins públicos e residências.

Oliveira (1998) descreveu que o alecrim é um subarbusto bastante ramoso e densamente foliado cujo caule, geralmente, mede entre 1 a 2 metros de altura e apresenta secção transversal obtuso tetragonal. Apresenta ramos geralmente opostos e um tanto pubescentes. As folhas são sésseis, lineares, inteiras, coriáceas e persistentes. Possuem disposição oposta e margens fortemente revolutas e, na página superior, são verdes e pontuado-rugosas ao passo que, na página inferior, são branca tomentosas. Medem entre 2 a $3,5 \mathrm{~cm}$ de comprimento por 2 a $4 \mathrm{~mm}$ de largura. A nervura mediana é bastante proeminente do lado da página inferior. As flores acham-se reunidas em pequenos racimos axilares, são pouco numerosas e curtamente pediceladas. $O$ cálice é tomentoso-pubescente e possui coloração variando de verde até tonalidades purpúreas. A corola é bilabiada e de coloração azulada, sobre a qual se inserem dois estames providos de uma única teca fértil e a outra transformada em alavanca. O gineceu possui ovário súpero bicarpelar e falsamente tetralocular por invaginação dos carpelos. O estilete é inserido

\footnotetext{
1 PECKOLT, T.; PECKOLT, G. História das plantas úteis do Brasil. Rio de Janeiro: Typ. Laemert, 1888-1914. 8v.
} 
ginobasicamente. O ovário se assenta sobre um disco glandular unilateralmente expandido e saliente. $O$ fruto seco se separa, caracteristicamente, em quatro frutículos ou núculas.

Segundo crendice popular, na Grécia Antiga, curava-se a memória fraca com um ramo de alecrim atrás da orelha. Entre os romanos, que o batizaram de rosa do mar, ou ros marinus, a crença era outra: a planta simbolizava o amor e a morte e, por isso, era plantado na soleira das portas, um hábito que perdurou até os tempos medievais na França. A Igreja Católica Apostólica Romana, coincidentemente, usa o alecrim nos seus rituais, queimando-o no incenso (Ervas e Temperos, s.d).

Muñoz (2000) relatou que os nomes genéricos, provêm dos vocábulos latinos ros, garoa e marinus mar, porém "garoa do mar" parecia indicar o habitat de uma espécie típica da bacia do Mediterrâneo. Os etimologistas opinam que o nome provém da união dos vocábulos gregos rhos arbusto e myrinos aromático, característica da planta, mas a primeira interpretação é a mais usual.

Giacometti (1989) afirmou que o alecrim é uma das plantas aromáticas mais difundidas na bacia do Mediterrâneo, pois, além de existir em estado silvestre, é cultivado para fins condimentares, ornamentais e para extração industrial de óleo essencial, sobretudo na França, na Espanha e na Itália.

A sua composição química revela que contém pineno, canfeno, borneol, cineal, lineol, taninos e óleos (Albuquerque, 1989). Suas flores e suas folhas são úteis no tratamento da asma, da coqueluche, da fraqueza, da gripe e outros (Moreira, 2002). Possui as seguintes propriedades terapêuticas: estimulante digestivo, antiespasmódico e contra o reumatismo articular, carminativo, emenagogo, desinfetante, anti-séptico, colagogo, ou seja, atua sobre a secreção biliar. Em doses elevadas é tóxico e abortivo. Usa-se em banhos para lavar ferida, como infusão e em implastros para contusões. As folhas secas em pó são cicatrizantes. O alecrim também favorece a menstruação e externamente é empregado para combater dores articulares. Também pode ser usada em abcessos, asma, doenças brônquicas, febres, gripe, hemicrania, 
hidropisia, catarro intestinal, coqueluche e queda de cabelo (Albuquerque, 1989; Balbach, s.d.; Von Hertwig, 1986).

De acordo com Glória (1995) as folhas de alecrim, tanto frescas como dessecadas, exalam forte e agradável perfume adocicado de incenso e cânfora. Isto se deve a presença de estruturas que secretam substâncias lipofilicas, através de seus tricomas secretores de óleos essenciais.

A oleoresina do alecrim é eficiente antioxidante para o óleo de soja e alimentos contendo beta-caroteno, sendo largamente utilizado na indústria de alimentos e cosméticos. Por ser rico em cânfora, o óleo essencial de alecrim é muito utilizado em perfumaria e na medicina (Farag et al., 1989; Chen et al., 1992; Maranca, 1986).

A propagação do alecrim pode ser realizada por sementes ou através de estacas, porém a propagação por sementes é lenta, levando a planta de dois a três anos para atingir a idade adulta, além de aumentar a variabilidade genética das novas plantas; o mesmo não ocorre quando essa planta é propagada vegetativamente através de estacas, pois, as características genéticas das plantas matrizes são mantidas (Von Hertwig, 1986). Segundo este mesmo autor, o alecrim é uma planta cujas qualidades aromáticas são melhores quando o solo é seco, pobre em nutrientes, leve e bem drenado, embora esta planta vegete bem com notável vigor em solos ricos em nutrientes. A colheita deve ser iniciada antes ou tão logo se inicie também o período de floração intensa, a partir do segundo ou terceiro ano de vida da planta.

\subsubsection{Aspectos Gerais do Bálsamo (Sedum dendroideum subsp. praealtum (DC.) R.T. Clausen)}

De acordo com a classificação de Cronquist (1981), o bálsamo ocupa a seguinte posição taxonômica:

Divisão: Magnoliophyta

Classe: Magnoliopsida 
Subclasse: Rosidae

Ordem: Rosales

Familia: Crassulaceae

Gênero: Sedum

Espécie: Sedum dendroideum subsp. praealtum (DC.) R.T. Clausen

A familia Crassulaceae é composta por 25 gêneros, cerca de 2.500 espécies, com distribuição cosmopolita (exceto Austrália e Polinésia), sendo porém, mais comum em regiöes áridas, temperadas ou de altas temperaturas (Cronquist, 1981).

Martins et al. (2000) descreveram ser ela originária da África do Sul e Ásia. É uma planta herbácea, folhas suculentas, flores amarelas, atingindo entre 30 e $50 \mathrm{~cm}$ de altura. Possui um sabor levemente ácido. É emoliente, usado em inflamações gastrintestinais e da pele, como cicatrizante. A parte usada são as folhas frescas. Multiplica-se por estaquia, e o plantio no local definitivo é feito no espaçamento de $40 \times 50 \mathrm{~cm}$. Esta planta tem condições mais favoráveis ao seu desenvolvimento com luz plena e ambiente pouco úmido.

Lorenzi (2001) mencionou que o bálsamo é uma planta originária de áreas semi-desérticas do México, de $30-60 \mathrm{~cm}$ de altura, com folhas carnosas, planas, lisas, espatuladas, recurvadas e reunidas em verticilos, suas inflorescências são terminais, ramificadas, com numerosas flores amarelas, formadas no outono e inverno. É cultivada como planta isolada, ou em grupos, a pleno sol, em terra fértil e permeável, bem como em jardins de pedras. $O$ sumo de folhas é tido como cicatrizante. É tolerante a seca e a geadas.

Segundo Furlan (1996), a propagação do bálsamo (Sedum praealtum) se dá especialmente por estaca de galhos e de acordo com IAPAR $^{2}$, citado por Furlan (1996), estas devem ser plantadas em covas no espaçamento $0,5 \times$ $0,5 \mathrm{~m}$ quando as plantas tiverem de cinco a oito folhas definitivas.

${ }^{2}$ INSTITUTO AGRONÔMICO DO PARANÁ. Plantas medicinais. Londrina, 1994. 


\subsubsection{Aspectos Gerais da Carqueja (Baccharis trimera (Less.) D.C.)}

De acordo com a classificação de Engler, revista por Melquior (1964), a carqueja ocupa a seguinte posição taxonômica:

Divisão: Magnoliophyta

Classe: Magnoliopsida

Subclasse: Asteridae

Ordem: Asterales

Familia: Asteraceae

Subfamília: Asteroideae

Tribo: Asteraea

Subtribo: Baccharidinae

Gênero: Baccharis Linnaeus

Espécie: Baccharis trimera (Less.) D.C.

Segundo Sá (1992), as plantas pertencentes à familia das Compositas são cosmopolitas, sendo encontradas em todos os continentes, com exceção do Antártico. São muito abundantes nas regiões montanhosas e em zonas áridas, porém escassas nas selvas tropicais baixa, sendo seu número insignificante na região Amazônica.

De acordo com Corrêa et al. (1998) e Souza et al. (1991), a carqueja é conhecida também como cacália-amarga, carque, carqueja-amarga, carqueja amargosa, quina-de-condamine, vassoura, carqueja do mato, carquejinha e tiririca de balaio.

O gênero Baccharis com cerca de 120 espécies no Brasil, possui distribuição predominantemente extratropical, ocorrendo principalmente na região Sul (Barroso, 1991). 
Borella et al. (2001) citando Souza ${ }^{3}$ mencionaram que, o gênero Baccharis, incluíndo em Asteraceae, é constituído por cerca de 400 espécies, muitas das quais semelhantes entre si e com uso na medicina popular, sendo utilizadas indistintamente contra reumatismo, anorexia, gripes e resfriados, mas principalmente no tratamento de problemas digestivos e hepáticos.

Vários estudos apontam que o gênero Baccharis é potencialmente indicado como fornecedor de óleo essencial na indústria, apresentando diversas utilidades, dependendo da espécie, sendo usado em perfumaria, uso terapêutico sem efeitos tóxicos, droga anti-reumática, entre outros (Silva e Grotta, 1971; Loayza et al., 1995; Suttisri et al., 1994; Jakupovic, 1990; Queiroga et al., 1996).

Corrêa Júnior et al. (1994) destacaram a denominação popular de carqueja amargosa, e descreveram a planta como um arbusto ereto e ramoso, com altura média entre 20 e $80 \mathrm{~cm}$, caule lenhoso, alado em sua extensão, com alas seccionadas alternadamente, levemente nervado, folhas bastante reduzidas e ovais, inflorescência em capítulos quase sempre aglomerados, de coloração amarela e fruto aquênio, linear glabro. Destacaram ainda, sua origem, supostamente, brasileira nascendo espontaneamente em quase todo o território nacional, sendo o Paraná considerado o centro de dispersão no país. Citaram que essa espécie ocorre até $2.800 \mathrm{~m}$ de altitude, sendo comum em campos e beiras de estradas, numa grande variedade de solos e com florescimento indiferentemente no verão e no inverno. Para a comercialização utiliza-se a planta toda, com descarte apenas de galhos maiores que $7 \mathrm{~mm}$.

Souza et al. (1991) descreveram a planta como um subarbusto aromático com cerca de $80 \mathrm{~cm}$ de altura, possuindo ramos lenhosos tri-alados, folhas ausentes, flores unisexuadas, branco-amareladas, localizadas nas extremidades dos ramos. Citaram a presença de óleos essenciais na parte

${ }^{3}$ SOUZA, M.P.; OLIVEIRA MATOS, M.E.; ABREU MATOS, F.J. Constituintes químicos ativos de plantas medicinais brasileiras. Fortaleza: UFC, Laboratório de Produtos Naturais, 1991. p.223-228. 
aérea e nas raizes, tendo propriedades amargas e utilização como estomáquico, sendo citada na medicina popular como anti-reumático, antihelmíntica, para doenças do fígado, gastroenterites, diabetes, anorexia, gripe, resfriado e para uso externo em feridas e ulcerações. Há estudos que constataram, ainda, ação hipoglicemiante e inibição do protozoário causador da doença de Chagas (Tripanossoma cruzi).

Barroso (1973) descreveu-a como subarbusto glabro, glutinoso, ramificado; com as alas dos ramos medindo aproximadamente 0,5-1,5 cm de largura; folhas muito reduzida, ovais; capítulos, geralmente aglomerados, formando espigas interrompidas, que se ordena em inflorescências paniculiformes, com ramificações simples; invólucro do capítulo feminino com 5$6 \mathrm{~mm}$ de altura e 2-3 mm de diâmetro, com 3-4 séries de brácteas involucrais glabras, agudas ou acuminadas; flores de 30-40, com corola de 3-4 mm de comprimento, com ápice truncado, envolvendo frouxamente o estilete; aquênio glabro, com mais ou menos $1-1,5 \mathrm{~mm}$ de comprimento, 10 estriado estilete com 4-6 $\mathrm{mm}$ de comprimento; invólucro do capítulo masculino com cerca de 4-4,5 $\mathrm{mm}$ de altura e $5 \mathrm{~mm}$ de diâmetro, com brácteas involucrais ovaladas, glabras; corola de flor masculina com mais ou menos $3,5-4 \mathrm{~mm}$ de comprimento, com limbo dividido em lacínios longos, enrolados em espiral.

Sá (1992) citou que o princípio amargo da carqueja é devido ao óleo essencial, que por causa de suas propriedades, facilita a digestão, ativando a secreção de todas as glândulas. Estas propriedades justificam o uso popular da carqueja contra os distúrbios gastrointestinais, sendo também utilizada contra a dispepsia, a diarréia e as afecções gástricas, intestinais e hepáticas, ativando tais funções. Seu óleo também é indicado como droga anti-reumática, devido à presença de carquejol e acetato de carquejila.

O óleo essencial de algumas espécies de Baccharis é obtido em escala industrial no Sul do Brasil. O valor comercial desses óleos varia em função dos teores de nerolidol e acetato de carquejila, embora seus constituintes majoritários sejam o carquejol $(9 \%)$ e o acetato de carquejila (45\%). O carquejol 
é a substância mais estudada do ponto de vista farmacológico, embora não haja correlação entre suas propriedades e o emprego popular da planta. Os vapores de carquejol, quando inalados em grandes quantidades, são irritantes para as mucosas ocular e nasal. Experiências efetuadas em camundongos e em ratos, tendo o carquejol em solução no óleo de oliva, permitiram concluir que o carquejol tem baixa toxicidade (Souza et al., 1991).

Lactonas diterpênicas isoladas da parte aérea de $B$. trimera apresentaram ação contra as cercarias do Shistosoma mansoni, que são as formas de transmissão da esquistossomose. Mostraram também ação letal para - molusco Biomphalaria glabata, que é o hospedeiro intermediário do $S$. mansoni (Castro, 1996).

De acordo com Leal \& Silva (1996) a carqueja possui como constituintes químicos ativos: pinenos, canfeno, carquejol, acetato de carquejila, e outros constituintes. O carquejol é a susbtância mais estudada, do ponto de vista farmacológico, parecendo não haver correlação entre o seu efeito e o uso popular da planta. Mol et al. (2003), avaliando a influência do nivel de irradiância na qualidade do óleo essencial em $B$. trimera, constataram que o composto majoritário nos três níveis de irradiância foi o espatulenol, e identificaram outros compostos como palustrol, epiglobulol, aromadrendenepoxido [I] e [II], a-terpineol, fitol, acetil eugenol, viridiflorol e guaiol.

Segundo Lorenzi \& Matos (2002), essa planta é amplamente utilizada no Brasil na medicina caseira, hábito este herdado de nossos indígenas que há séculos já faziam uso da mesma para o tratamento de várias doenças. $O$ primeiro registro escrito do seu uso no país data de 1931, informando o emprego da infusão de suas folhas e ramos para o tratamento da esterilidade feminina e da impotência masculina $e$, atribuindo-a propriedades tônicas, febrifugas e estomáquicas. 
Rodrigues et al. (1994) estudaram a toxicologia pré-clínica da carqueja, concluindo que nenhum efeito tóxico-colateral foi causado pelo chá de carqueja na concentração utilizada popularmente.

A carqueja apresenta uso medicinal difundido, pela medicina popular (Marquesini, 1996; Di Stasi et al., 1994) ou por programas oficiais de saúde pública (Sacramento et al., 1996; Pires, 1996; Moresco, 1996), na forma de infusão e tintura alcoólica.

A carqueja é também utilizada na indústria de cervejaria, como substituto do lúpulo; na aromatização de refrigerantes e de licores, devido à presença de substâncias resinosas e óleo essencial; e na apicultura, sendo os méis considerados, dentre os silvestres, os mais saborosos (Castro, 1996).

Magalhães (1997) mencionou que a produção de mudas da carqueja por estacas, a partir de folhas, deve ser realizada nos meses mais quentes do ano. Também é importante um rigoroso controle da umidade do substrato (evitar excesso ou falta de água).

A propagação da carqueja se dá por sementes ou por mudas retiradas da planta adulta, por divisão de touceira ou, ainda, por estaquia. A reprodução por sementes pode não dar os resultados esperados, em razão da demora que a planta terá para atingir o ponto de colheita (Corrêa Jr et al.,1994).

Castro et al. (1996), avaliando o efeito fitohormonal do biofertilizante líquido em diferentes substratos (areia, casca de arroz carbonizada e terra + areia + esterco na proporção de 1:1:1), no enraizamento de estacas de carqueja, concluíram que não houve influência do substrato e da imersão em biofertilizante ou água sobre o enraizamento das estacas.

A melhor época de plantio da carqueja está entre os meses de setembro e novembro, no espaçamento de $0,5 \times 0,3 \mathrm{~m}$. A cultura deve ser renovada a cada 3 - 4 anos (Corrêa Jr et al., 1994). De acordo com Martins et al. (1995), a carqueja pode ser plantada no espaçamento de $0,4 \times 1,0 \mathrm{~m}$, na época das chuvas. 
A disponibilidade de nutrientes do solo pode influir não só no desenvolvimento da planta, mas também no teor de princípios ativos (Scheffer, 1991). Dias et al. (1996) avaliaram o efeito das adubações químicas (0-300-600 $\mathrm{kg} / \mathrm{ha}$ de 4-14-8) e orgânica (0-15-30 t/ha de esterco de curral) na carqueja, concluindo que, com adubação orgânica, houve aumento na massa de matéria fresca, na massa de matéria seca e na altura das plantas. A porcentagem de óleo essencial não foi influenciada pela adubação.

$\mathrm{Na}$ comercialização de plantas medicinais, segundo Ming (1995), a exportação de ervas medicinais também vem acontecendo (dados do IBAMA, no aeroporto de Guarulhos - SP), e as indicações mostram a saída de 108 toneladas de plantas medicinais, no valor de US\$390 mil, destacando-se, dentre as espécies mais exportadas, a carqueja. Os países para os quais 0 Brasil mais exporta são: Japão, Coréia do Sul, Alemanha e Estados Unidos. Cerri (1995) citou que, em 1991, houve a nivel nacional, aumento do consumo da carqueja; mas, depois entrou a concorrência e os preços caíram. Agricultores de Araucária - PR comercializaram a carqueja a 50 centavos de real por quilo.

\subsubsection{Aspectos Gerais do Tomilho (Thymus vulgaris L.)}

De acordo com a classificação de Cronquist (1981), o tomilho ocupa a seguinte posição taxonômica:

Divisão: Magnoliophyta

Classe: Magnoliopsida

Subclasse: Asteridae

Ordem: Lamiales

Familia: Lamiaceae

Genero: Thymus

Espécie: Thymus vulgaris L. 
Originário da Europa, pertencente à família Labiatae, o Thymus vulgaris também conhecido por Tomilho, é uma espécie herbácea anual ou bianual nas condições climáticas de Campinas - SP. A sua propagação pode ser realizada por estacas, tomando-se o cuidado de se utilizar plantas bem sadias, que apresentem características de interesse (Magalhães, 1997). As folhas são pequenas, com pecíolo curto lanceoladas ou lineares, de até $9 \mathrm{~mm}$ de comprimento e até $2 \mathrm{~mm}$ de largura, com bordos voltados para baixo, esbranquiçadas e glandulosas. As flores formam glomérulos, que parecem capítulos globosos, axilares e terminais, de cor rosada ou branca. A sumidade floral tem cheiro aromático suave e muito agradável, devido à essência contida em pêlos de cor avermelhada, situados nas folhas (Morgan, 1994; Corrêa Jr. et al., 1994; Maranca, 1986).

O tomilho já era conhecido, tanto para a medicina como no uso condimentar, pelos gregos e romanos (Morgan, 1994). Foi usado como incenso nos templos da Grécia antiga, onde era considerado sinônimo de graça, elegância e coragem, e também como ingrediente das substâncias usadas pelos egípcios para embalsamar corpos. No período das cruzadas, as mulheres - colocavam na roupa dos cavaleiros, para desejar-lhes sorte e bravura nas batalhas (Ervas e temperos, s.d.; Giacometti, 1989).

No Brasil, é vulgarmente conhecido como poejo e segurelha. As propriedades farmacológicas do tomilho são atribuídas principalmente à sua essência habitualmente rica em timol. Outros componentes do tomilho são: carvacrol, álcoois, hidrocarbonetos, resina, tanino, saponósidos e vitaminas B1 e C (Hertwig et al., 1986).

É considerado excitante das funções circulatórias e cerebrais, bem como dotado de propriedades antiespasmódicas, diuréticas, sudoríficas e desinfetantes (Morgan, 1994).

Para fins aromáticos e em fitoterapia se utilizam as sumidades floridas, isto é, as extremidades de ramos com as folhas e flores. Para a extração de óleo essencial alguns fabricantes utilizam a planta inteira florida, com exclusão 
das raizes. Em climas quentes tropicais, o tomilho não floresce nunca, e nesse caso especialmente, só se utilizam suas folhas (Hertwig et al., 1986).

Segundo ainda os mesmos autores, o tomilho é encontrado abundantemente no estado silvestre em terrenos secos e quentes da flora mediterrânica, e em especial nas colinas áridas. Em Portugal, desenvolve subespontaneamente até 1.500 metros de altitude. Na Espanha, vegeta nos páramos de Lérida e Bajo Aragón. É silvestre em montanhas áridas do Sul da França, bem como na Algéria e Marrocos. O tomilho é cultivado na Europa, especialmente na Hungria, na Alemanha, nas províncias de Múrcia e Almeria da Espanha, e no Sul da França. O tomilho é uma cultura já aclimatada no Brasil.

Para Maranca (1986), o cultivo do tomilho não apresenta particulares exigências, a não ser regiões secas, áridas, expostas ao sol e solos pedregulhentos, mas leves e possivelmente calcários; por ser uma planta de solos pobres, evitando-se umidade excessiva, e terras compactadas. A colheita é feita em plena floração, cortando a planta inteira. Com a secagem, o tomilho perde cerca de $2 / 3$ de seu peso. Até poucos anos antes da última Grande Guerra, o sul da França, um dos maiores produtores, obtinha cerca de 100 t de óleo essencial de tomilho por ano, em grande parte destinado à fabricação de sabonetes, de perfumes, e à extração do timol, por suas propriedades antimicóticas, já usado no passado para preservar livros, documentos antigos e objetos de arte.

\subsection{Considerações sob Propagação Vegetativa}

A propagação assexuada ou vegetativa se baseia na regeneração de um vegetal a partir de células somáticas. Fundamenta-se no princípio de que toda célula é totipotente (Simão, 1971).

A propagação vegetativa por meio do uso de estacas é uma técnica agronômica antiga, embora ainda muito empregada devido a simplicidade, rapidez com que pode ser executada e uniformidade dos indivíduos obtidos 
(Mitchell \& Marth, 1950). A estaquia é caracterizada pela separação da plantamatriz de uma parte multicelular, que produzirá uma nova planta independente e idêntica à originária, exceto quando ocorre algum tipo de mutação (Hidalgo, 1993; Regina et al., 1988).

As estacas oriundas do caule são as mais utilizadas na propagação. Estas podem ser divididas em três grupos, de acordo com a natureza do lenho: estacas lenhosas (apresentam tecidos lignificados, ausentes de folhas e coletadas na época da poda hibernal); estacas herbáceas (apresentam tecidos tenros, coletadas na época de desenvolvimento vegetativo da planta, requerendo a presença de folhas) e estacas semilenhosas ou semiherbáceas, que apresentam um estágio intermediário entre os dois extremos, sendo coletadas no final do verão, ainda foliadas (Hartmann et al., 1990; Fachinello et al., 1994). Segundo estes autores, existem grandes diferenças na capacidade de enraizamento entre os diferentes grupos de estacas, dependendo da espécie em questão $e$, até mesmo, entre plantas da mesma espécie.

A escolha do tipo de estaca a ser utilizado para o enraizamento depende da espécie que está sendo trabalhada. Muitas vezes, para uma mesma espécie, mais de um tipo de estaca pode ser utilizado, com resultados igualmente satisfatórios (Hartmann et al., 1990).

Diferentes percentuais de enraizamento foram constatados por Mehrotra \& Singh (1991), quando utilizaram três tipos de estacas de ameixeira (apical, mediana e basal), na cultivar 'Kala Amritsari', concluindo que as porções basais apresentaram maior capacidade de enraizamento. Carrijo et al. (2002) chegaram a mesma conclusão, testando diferentes posições de coleta de estacas no ramo, e no enraizamento de estacas lenhosas do porta-enxerto de Pyrus calleryana Dcne. Salomão et al. (2002), trabalhando com estacas de maracujazeiro-doce e amarelo, constataram que as estacas retiradas da porção basal e mediana proporcionam maior potencial de enraizamento, porém, estacas provenientes da porção apical dos ramos, demonstram propiciar melhor 
qualidade do sistema radicular, o que pode ser uma vantagem no estabelecimento das mudas no campo.

Zancan (1989) utilizou estaca semilenhosa de ameixeira para plantio, verificando elevada percentagem de enraizamento nas estacas retiradas da porção apical dos ramos devido ser a região de síntese de auxina.

Em pessegueiro, estacas apicais semi-lenhosas contendo uma gema apical enraizaram em maior percentagem do que aquelas retiradas de porções basais dos ramos (Marini, 1983). Embora essas estacas contendo uma gema apical não possam ser consideradas herbáceas, ela é menos madura que a da porção basal, logo, essa resposta pode ser devido às diferenças na maturidade fisiológica em detrimento da posição em si (Couvillon, 1988).

Mendonça (1997), trabalhando com alecrim-pimenta (Lippia sidoides Cham.) sob tela de sombreamento constatou que, o melhor tipo de estaca foi a herbácea com a presença de folhas.

Jawanda et al. (1990), comparando estacas basais e apicais de ramos das cultivares de ameixeira japonesa Kataru Chak e Lari, verificaram que, as estacas apicais apresentaram os maiores percentuais de enraizamento.

Souza (1998) revelou que a produção de biomassa em tanchagem (Plantago major L.) apresentou efeito significativo da intensidade luminosa. A produção de biomassa, seca e fresca das folhas e das inflorescências, o sistema radicular, a área foliar e a altura foram influenciados pelo nível de irradiância, sendo mais expressiva em maior nível.

A formação de raizes adventícias em estacas inicia-se a partir de um grupo de células denominadas células iniciadoras de raízes; as quais possuem núcleos grandes, centralizados e pequenos vacúolos. O meristema secundário sofre divisões mitóticas formando pequenos conjuntos de células que continuam a se dividir, diferenciando-se e formando os primórdios radiculares que ligam seus vasos vasculares aos vasos vasculares adjacentes existentes na planta. Em seguida, por crescimento, o primórdio atravessa o córtex e 
emerge na epiderme, constituindo a nova raiz (Hartmann e Kester, 1983; Lovell e White, 1986).

A capacidade de enraizamento de algumas espécies é inferior devido principalmente a componentes bioquímicos da própria planta, como também as condições ambientais a que são submetidas (Deschamps, 1993). Segundo Haissing (1986), as diferenças na capacidade de enraizamento são devido a fatores genéticos e atividade de enzimas específicas.

As raízes originárias das estacas são classificadas como adventícias, ao contrário do que ocorre na propagação sexuada, onde são formadas raízes do tipo pivotante (Fachinello et al., 1994; Pasqual et al., 2001). Em estacas herbáceas, as raízes adventícias são formadas na região do floema e as estacas lenhosas, as raízes adventícias originam no câmbio, próximas ao cilindro vascular (Alvarenga \& Caravalho, 1983).

De acordo com Hartmann et al. (1990), o processo de desenvolvimento das raizes adventícias é dividido em três estágios: a desdiferenciação celular, onde as células sofrem novamente diferenciação e retornam ao estágio meristemático; a diferenciação das células meristemáticas em primórdios radiculares; o crescimento e emergência de novas raízes.

Segundo Fachinello et al. (1994), as raízes formadas nas estacas são respostas ao traumatismo produzido pelo corte na base da estaca. Com a lesão ocasionada pelo corte, ocorre traumatismo nos tecidos do xilema e floema, seguido por um processo de cicatrização, formando-șe, assim, uma capa de suberina, responsável pela redução da desidratação na área lesada. Nesta região, muitas vezes, é formada uma massa celular parenquimatosa e desorganizada, denominada de calo.

Torres \& Caldas (1990) conceituaram calo como sendo um grupo ou massa de células não organizadas, em crescimento desorganizado e com certo grau de diferenciação. $O$ calo pode ter sua origem a partir do câmbio vascular, do córtex ou da medula, cuja formação representa o início do processo de regeneração (Fachinello et al., 1994). 
A capacidade de uma estaca emitir raizes está em função de fatores endógenos, localizados internamente nas estacas e fatores exógenos, ou seja, influência de fatores externos (Fachinello et al., 1994). Para estes autores, a formação de raizes adventícias deve-se a interação de tais fatores, principalmente, a translocação de substâncias localizadas nas folhas e gemas, onde está o centro de produção de substâncias hormonais, que são translocadas via floema para as diversas regiões da planta. Essas substâncias controlam a divisão celular em tecidos de plantas, podendo ser limitantes ou estimulantes nos processos fisiológicos (Torrey, 1996).

De acordo com Janick (1966), a presença de folhas e gemas tem grande influência no enraizamento de estacas de caule. Entretanto, em muitas espécies o efeito da gemas deve-se, principalmente, à produção de auxina, enquanto que o estímulo provocado pelas folhas está relacionado com a produção de carboidratos. Em outras espécies, o material de reserva está estocado no caule, não requerendo, assim, a presença de folhas, indicando que existem co-fatores suficientes na estaca para a iniciação do enraizamento (Weaver, 1972).

Segundo Evans (1973), o crescimento do sistema radicular é menor quando da redução da disponibilidade de luz, mas, o efeito é nitidamente indireto, pela redução do fornecimento de fotoassimilados a partir da parte aérea. Por sua vez, o crescimento da parte aérea depende das raizes pelo fornecimento de água, elementos minerais e alguns hormônios. Logo, devem existir mecanismos que possibilitam condições minimas de equilibrio entre estas duas partes, de modo que uma não limite o desenvolvimento da outra. De modo geral, considera-se que folhas do topo suprem fotoassimilados para as folhas mais jovens em desenvolvimento, folhas posicionadas ao centro suprem o caule e folhas posicionadas mais abaixo, fornecem fotoassimilados para a parte mais inferior do caule e raizes (Wilkins, 1985; Wardlaw, 1990).

Morales (1990) mencionou que muitos autores, até agora, têm estudado esse fato, concluindo que, em muitas espécies, não é necessário nenhum 
estímulo ao enraizamento, no entanto para outros a formação de raízes é dependente das folhas, verificando que o estímulo necessário é proveniente das mesmas. Fachinello et al. (1994) afirmaram que a formação de raizes adventícias deve-se à interação de fatores que existem nos tecidos da estaca com substâncias produzidas e translocadas das folhas e gemas.

Além disso, as folhas jovens são responsáveis pela produção de auxinas encontradas naturalmente na planta e pela síntese de vitaminas, especialmente B6 (piridoxina) precursora do ácido naftalenoacético (ANA) (Devlin, 1975; Wareing et al., 1981).

Pereira et al. (1983), objetivando determinar quais os melhores tipos de estacas de goiabeira, concluiram que as obtidas da porção apical dos ramos, com dois nós e um par de meias folhas, promoveram os maiores percentuais de enraizamento.

Fachinello et al. (1994) relataram que, além das auxinas, existem outras substâncias de ocorrências naturais responsáveis pelo enraizamento, denominadas de co-fatores, a exemplo do ácido isoclorogênico e terpenóides oxigenados, que atuam sinergicamente com as auxinas no processo de enraizamento.

Segundo Pasqualetto (1995), a maioria das espécies responde positivamente ao tratamento com auxina. Contudo, os benefícios de tratamento com auxinas podem ser evidentes mesmo nas espécies que enraízam na sua ausência, quer seja aumentando a porcentagem de enraizamento antecipando a indução, ou aumentando o número, qualidade e uniformidade das raízes (Blazich, 1988 e Hartmann et al., 1990).

Silva (1998) observou que a aplicação de ANA ou IBA em estacas de alecrim nas quatro estações do ano, não aumentou significativamente o número de estacas enraizadas as quais, não variaram significativamente daquelas tratadas apenas com água, sendo que, ao final do inverno as estacas tratadas com altas doses de auxina apresentaram um baixo número médio de estacas 
enraizadas, quando comparadas com quase $100 \%$ daquelas tratadas com água.

As características do substrato para enraizamento podem ser muito importantes para o sucesso do enraizamento de estacas (Couvillon, 1988). No entanto, dependendo da espécie vegetal e cultivar e/ou substrato analisado pode até não afetar (Pokorny \& Austin, 1982). Segundo Hartmann et al. (1990), o substrato para o enraizamento apresenta as funções de dar suporte às estacas durante o período de enraizamento; prover umidade às estacas; e permitir a penetração do ar na base da estaca.

Para Long (1932), estacas de muitas espécies cultivadas em solos arenosos produzem raizes escassamente ramificadas, podendo comprometer a sobrevivência desse material por incapacidade das mesmas em absorver os elementos essenciais ao seu desenvolvimento.

Chauhan \& Maheshwari (1970) e Myre \& Schwaetze (1948) obtiveram altas percentagens de enraizamento de estacas de plantas herbáceas tratadas com AIB e colocadas no meio de enraizamento com areia.

Vários autores mostraram que as estacas de muitas espécies enraizam com facilidade numa grande diversidade de substratos. Em estacas de plantas que enraízam com dificuldade, o meio pode influir, não só na percentagem de enraizamento como também na qualidade do sistema radicular formado (Janick, 1968; Mahlstede \& Haber, 1957).

A areia é um dos meios mais utilizados para o enraizamento de estacas, e relativamente baratos e de fácil aquisição. Porém, não retêm umidade como os outros meios, sendo necessária irrigação com maior freqüência e sua granulometria deve ser de tamanho médio para propiciar melhor obtenção de estacas enraizadas (Janick, 1968; Kramer \& Kozlowski, 1972; Mahlstede \& Haber, 1957). 


\subsection{Sistema de cultivo}

O uso do plástico na agricultura é tão diversificado que é difícil descrever todas as suas utilidades, porém, podem-se citar algumas como: cobertura de casas de vegetação, túneis de cultivo, cobertura do solo, impermeabilização de canais e reservatórios, sacos para mudas, lonas, etc. A maior difusão do uso do filme plástico foi o principal fator para o desenvolvimento e aumento do número da produção em casas de vegetação no mundo todo. O centro de referência inicial para o cultivo protegido é a Holanda, mas hoje em todo o mundo este tipo de produção vegetal já é prática consagrada (Carmo Júnior, 2000).

A utilização do termo estufa é mais adequada para estruturas simples, com a função de guarda chuva; para construções com controle do ambiente interno utiliza-se o termo casa de vegetação, embora a denominação inicial tenha se popularizado para qualquer estrutura (Bliska Junior \& Honório, 1996).

As primeiras experiências com cultivo de plantas sem solo foram realizadas por volta do ano de 1600 . Porém, antes disso, nos jardins da Babilônia; nos jardins Astecas, no México, e nos jardins da China imperial, plantas já eram cultivadas sem o uso de solo. Hieróglifos escritos centenas de anos antes de Cristo também citam o cultivo de plantas em água. Antes de Aristóteles, Theophrasto (372-287 a.C.) realizou vários ensaios com nutrição vegetal (Resh, 1997).

Poucos estudos têm sido desenvolvidos para comparar a produção das espécies produzidas em ambiente protegido com as produzidas em cultivo tradicional, especialmente quando se trata de plantas aromáticas. Também são pouco estudadas as características aromáticas dessas plantas relacionadas às formas de cultivo (Fernandes et al., 2004).

$\mathrm{Na}$ busca do homem por soluções simples, a plasticultura pode contribuir para incrementar a produção, a qualidade e o retorno financeiro, na condição atual do produtor. Esse retorno financeiro pode ser obtido, dentre outras formas, com a diminuição dos gastos com o preparo do solo, a utilização racional dos 
insumos como fertilizantes e herbicidas e, principalmente, com a redução no consumo de água para irrigação (Pinto, 1997).

Esse mesmo autor cita que a água é fator fundamental ao desenvolvimento e crescimento de uma planta, pois, afeta, além de inúmeros processos fisiológicos, o desenvolvimento do sistema radicular, refletindo na absorção de nutrientes pelas raízes. A produção de hortaliças, de modo geral, requer irrigações freqüentes com água de boa qualidade, o que reflete diretamente no custo da produção. Porém, tanto o excesso quanto a falta de água são prejudiciais à planta.

Segundo Oliveira (1996), a irrigação excessiva implica: a) maior volume de água bombeado, o que resulta em alto custo com energia; b) maior percolação profunda, a qual contribui para a lixiviação de fertilizantes; c) degradação da qualidade da água; e d) redução da produtividade das culturas.

O "floating" consiste em um tanque de aproximadamente $30 \mathrm{~cm}$ de altura, tendo largura e comprimento suficientes para acomodar o número de bandejas desejadas, preenchidas com uma solução de água e adubo solúvel, onde as bandejas de poliestireno expandido são colocadas e ficam boiando.

Para Borne (1999) o sistema floating consiste na utilização de bandejas com substratos que servirá de sustentação para a muda, sendo que essa bandeja ficará mergulhada em solução nutritiva, que fornecerá os elementos nutritivos que a planta necessita para formar-se. $O$ que muda fundamentalmente na produção com a solução nutritiva, é que as bandejas estão dentro de um tanque ao rés do chão ou elevadas, mergulhadas, boiando, numa solução nutritiva. Esse processo de produção não dispensa uma estufa de filme plástico para produzir as mudas, dispensando porém totalmente a irrigação. A Companhia de cigarros Souza Cruz iniciou com seus plantadores de fumo essa maneira de produzir suas mudas. Esse mesmo autor fez um comparativo com a produção de mudas em bandejas suspensas, apresentando as seguintes vantagens: mudas mais vigorosas; maior rapidez na produção das mudas; mudas mais resistentes a doenças; água disponível sempre, não 
havendo necessidade de irrigações; o custo de produção das mudas é menor; dispensa menor quantidade de mão-de-obra e menos preocupações com a irrigação; garantia de produção de mudas. Entre as principais desvantagens, tem-se entre elas: se o tanque estiver rente do chão da estufa, o operador para tirar as bandejas do tanque, fica em posição incômoda para o trabalho; corre o risco de quebrar as bandejas de isopor ou danificá-las mais facilmente, pois ficam mais pesadas devido a água que está no substrato: e maior facilidade de contágio por doenças ou pragas, pois tem um meio líquido para propagação.

Verdial et al. (1999), estudando a influência do uso do "floating" na produção de mudas de tomate, concluíram que as bandejas que ficaram dentro do "floating" por todo o período experimental produziram mudas de maior altura, maior massa de matéria fresca das partes aérea e das raizes superiores.

Neitzke et al. (2003) avaliaram o efeito de diferentes vermicompostos na emergência da cultura da petúnia (Petúnia hybrida) em sistema flutuante de produção de mudas. Concluíram que o húmus fértil é eficiente em relação aos substratos alternativos para produção de mudas de petúnia, em sistema flutuante, em ambiente protegido.

O condicionamento nutricional com a utilização do "floating", em mudas de pimentão, proporcionou maior desenvolvimento, além de permitir o controle do desenvolvimento das mesmas, mostrando-se uma técnica viável e de fácil utilização (Verdial et al., 1998).

Fernandes et al. (2004), cultivando manjericão de folha larga e estreita em sistema "floating" sob diferentes substratos; concluíram que para as duas espécies estudadas, o sistema hidropônico possibilitou maior produtividade, com o rendimento e a composição química dos óleos essenciais das plantas não sofrendo alteração, evidenciando que o uso é adequado à produção de manjericão no sistema "floating" para comércio da planta fresca, sem prejuízo da característica aromática conferida pelos óleos essenciais.

Verdial et al. (2000), comparando métodos de formação de mudas de maracujazeiro amarelo, incluindo a técnica do "floating", concluíram que a 
utilização do sistema "floating" no condicionamento do desenvolvimento de mudas de maracujazeiro amarelo mostrou-se experimentalmente viável, permitindo o controle do desenvolvimento das mesmas e proporcionando um maior desenvolvimento inicial em campo.

Horner et al. (2003), avaliando o crescimento de mudas de tomate, através de sistema flutuante, em diferentes substratos, concluíram que as plantas produzidas em vermiculita apresentaram valores superiores para todas as características avaliadas.

\subsection{Produção de mudas}

A produção de mudas de alta qualidade e o desenvolvimento de sistemas de produção adequados é de fundamental importância para o sucesso do processo de transferência e implantação do cultivo de plantas aromáticas e medicinais. Dentre os sistemas de produção, os cultivos em ambientes controlados como estufas e sistemas hidropônicos são de fundamental importância. Esses sistemas permitem a obtenção de dados sobre a nutrição e desenvolvimento das plantas e propiciam opções de cultivo para algumas plantas exóticas de alto valor agregado, cuja produção local em campo é prejudicada pelas condições climáticas e/ou edafológicas da região. Os cultivos em ambientes controlados possuem também a vantagem de aumentar a produção por área, permitir a produção durante todo ano, limitar o uso de defensivos agrícolas (problema sério no caso de produção de óleos essenciais) e proporcionar condições nutricionais adequadas a cada período do desenvolvimento do vegetal (Serafini et al., 2001)

No Brasil, acredita-se que a maioria da produção das plantas medicinais são obtida através do extrativismo e com o desconhecimento botânico das espécies cultivadas. Segundo Ming (1994), há necessidade de se estabelecer técnicas agronômicas de manejo e cultivo com certa urgência em virtude da demanda crescente de matéria prima. A maior parte das espécies vegetais 
nativas, ou que já são aclimatadas no Brasil, é colhida por processos extrativos, sem que haja fiscalização eficiente por parte dos órgãos responsáveis. Estes problemas podem ser contornados por meio de pesquisas agronômicas, oferecendo subsídios para o cultivo a céu aberto ou como uma cultura convencional.

A produção de mudas de alta qualidade torna-se estratégica para quem deseja tornar mais competitiva sua produção, e aumentar a exportação. Considera-se que $60 \%$ do sucesso de uma cultura está em implantá-la com mudas de alta qualidade (Minami et al., 1994).

Dentre os vários recipientes existentes no mercado, pode-se dispor de tubetes ou bandejas de poliestireno expandido (isopor) para a formação de mudas, o que tem sido utilizado principalmente por grandes empresas produtoras de mudas.

As vantagens do sistema de produção de mudas em recipientes são múltiplas e justificam plenamente sua adoção (Tessarioli Neto, 1995). De acordo com Platt \& Opitz (1973), as vantagens do sistema de produção de mudas em recipientes incluem: maior controle da infecção e da contaminação por doenças fúngicas e por nematóides; crescimento mais intenso, devido ao uso de substratos mais elaborados; maior controle da fertilidade do substrato e do ambiente e a ausência de distúrbios radiculares no transplante. Porém, os autores apresentam como desvantagens desse sistema: produção de plantas menores para o transplante, as quais requerem maiores cuidados durante o primeiro ano; necessidade de replantio em um recipiente maior, quando a época de plantio prolonga-se; necessidade de coberturas com polietileno e sombreamento para controle do ambiente.

A eficiência do sistema de produção de mudas em recipientes é alta, principalmente quando se considera o número de plantas por área. No sistema de viveiros tradicional, a população está entre 80 a 160 mil plantas por hectare, enquanto no sistema em vasos, tem-se em torno de 400 mil plantas por hectare (Castle \& Rouse, 1991). 


\section{MATERIAL E MÉTODOS}

\subsection{Local de Realização do Experimento}

Os experimentos foram conduzidos na área experimental do Departamento de Produção Vegetal da Escola Superior de Agricultura "Luiz de Queiroz" da Universidade de São Paulo, no município de Piracicaba - SP, localizada a $22^{\circ} 41^{\prime} 30^{\prime \prime}$ de latitude Sul, $47^{\circ} 38^{\prime} 30^{\prime \prime}$ de longitude Oeste e $546 \mathrm{~m}$ de altitude em relação ao nível do mar.

De acordo com a classificação climática de Köppen para esta região, a fórmula climática resulta em Cwa, ou seja, subtropical úmido, com estiagem no inverno.

\subsection{Preparo do Material}

O material vegetal foi obtido junto ao campo de produção de plantas medicinais e aromáticas do Departamento de Produção Vegetal da Escola Superior de Agricultura "Luiz de Queiroz", no município de Piracicaba - SP.

$\mathrm{Na}$ tabela 1 estão discriminados os métodos de propagação que foram testados para cada espécie trabalhada. 
Tabela 1. Tipos de propagação de mudas para cada espécie

\begin{tabular}{lll}
\hline Nome da Planta & Propagação & Observações \\
\hline Alecrim & estacas & $\begin{array}{l}\text { As estacas foram retiradas das porções } \\
\text { apicais e basais dos ramos }\end{array}$ \\
Bálsamo & estacas & $\begin{array}{l}\text { As estacas foram retiradas apenas de folha } \\
\text { Carqueja }\end{array}$ \\
Tomilho & estacas & $\begin{array}{l}\text { As estacas foram retiradas das porções } \\
\text { apicais e basais dos ramos } \\
\text { As estacas foram retiradas das porções } \\
\text { apicais e basais dos ramos }\end{array}$ \\
\hline
\end{tabular}

\subsubsection{Tratamentos}

Foram utilizados três tratamentos, procurando-se avaliar tanto 0 enraizamento como, qual segmento do ramo produz mudas de melhor qualidade.

Os tratamentos foram assim denominados:

A - Testemunha, sistema convencional (bandeja de poliestireno expandido de 128 células preenchidas com Plantmax $\mathrm{HT} \otimes$ e mantidas sob casa de vegetação com irrigação intermitente);

B - Sistema "floating" (bandeja de poliestireno expandido de 128 células preenchidas com Plantmax $\mathrm{HT} \circledast$ e mantidas em "piscina" contendo apenas água, onde ficaram flutuando por todo período de desenvolvimento das mudas); C - Sistema de bandejas plásticas preenchidas com areia lavada (mantidas sob casa de vegetação com irrigação intermitente).

Para todas as espécies estudadas independente, do tipo de ramo vegetativo utilizado, seja ele apical ou não apical, todos foram submetidos aos três tratamentos acima, variando apenas a época do ano (Verão e Inverno). 


\subsubsection{Padronização das estacas}

As espécies propagadas por estacas apicais e não apicais (ver tabela 1) tinham em média $10 \mathrm{~cm}$ de comprimento com número indeterminado de gemas e folhas. Após a separação das partes apicais e basais, estas foram colocadas em bandejas de poliestireno expandido de 128 células contendo os respectivos substratos. Em seguida, as bandejas foram submetidas aos diferentes tratamentos: 1. convencional; 2. floating (permanência constante na água); e 3. caixa com areia lavada.

\subsection{Condução do experimento}

Instalado em casa de vegetação, a área experimental foi sistematicamente monitorada por meio de visitas rotineiras para a coleta de dados. Na medida em que foram sendo necessários, foram adotados os tratos culturais e reposição da água no sistema "floating".

As mudas para o tratamento $A$ e $B$, foram produzidas em bandejas de poliestireno expandido 128 células com substrato Plantmax $\mathrm{HT} \circledast$.

As mudas do tratamento $C$ foram produzidas em bandejas plásticas com areia lavada.

\subsection{Delineamento experimental}

O delineamento experimental utilizado foi o inteiramente casualizado, com 3 tratamentos e 4 repetições (item 3.2.1) e a unidade experimental foi de 16 plantas. Os dados obtidos foram submetidos a análises estatísticas apropriadas para cada espécie. Procedeu-se a análise de variância dos dados utilizando-se níveis de significância de $5 \%$ de probabilidade pelo teste $\mathrm{F}$. 


\subsection{Avaliações}

\subsubsection{Qualidade de enraizamento}

Foi atribuída uma escala de nota visual variando de 1 a 5 para o enraizamento das mudas. Sendo 1 , sem raízes ou péssimo enraizamento e 5 ótimo enraizamento.

\subsubsection{Peso de massa fresca da parte aérea e da raiz}

As mudas foram lavadas com água corrente e, em seguida, secas ao ar sobre papel toalha. As mudas foram seccionadas da parte aérea e as raizes separadas sendo pesadas em balança analítica.

\subsubsection{Peso de massa seca da parte aérea e da raiz}

Após a pesagem descrita no item anterior as amostras foram levadas para secar em uma estufa a $70^{\circ} \mathrm{C}$ em circulação forçada de ar, até atingir peso constante. Sendo em seguida pesadas em balança analítica. 


\section{RESULTADOS E DISCUSSÕES}

\subsection{Avaliação da produção de mudas do Alecrim}

Nas Tabelas 2, 3 e 4 são apresentados os resultados das avaliações de época do ano, o tipo de estaca e o sistema de cultivo.

Os dados referentes a qualidade do enraizamento (QE) avaliados no verão, (Tabela 2) mostram que houve um maior desenvolvimento das raízes quando comparado com o inverno. Isto demonstra que a escala de nota atribuída ao alecrim comprova a boa capacidade rizogenética no verão. Segundo Fachinello et al. (1994), estacas colhidas no verão apresentam-se mais herbáceas de modo geral, mostrando maior capacidade de enraizamento.

Tabela 2. Médias dos parâmetros para o alecrim (Rosmarinus officinalis L.) para qualidade do enraizamento (QE), peso de massa verde da parte aérea (PVPA), peso de massa verde de raiz (PVR) avaliadas no verão e inverno

\begin{tabular}{lrrr}
\hline ÉPOCA & QE & PVPA (g) & PVR (g) \\
\hline Verão & $2,7083 \mathrm{a}$ & $0,6027 \mathrm{~b}$ & $0,0893 \mathrm{~b}$ \\
Inverno & $0,8750 \mathrm{~b}$ & $11,0060 \mathrm{a}$ & $0,2824 \mathrm{a}$ \\
C.V. & $34,21 \%$ & $18,24 \%$ & $34,97 \%$ \\
\hline
\end{tabular}

Médias seguidas pelas mesmas letras minúsculas, nas colunas, não diferem estatisticamente entre si, pelo teste de Tukey-kramer, ao nivel de $5 \%$ de significância.

*Dados transformados $\log _{10} P V R$

Para os parâmetros peso verde da parte aérea (PVPA) e peso verde da raiz (PVR) (Tabela 2), pode se notar que no inverno houve um maior incremento em relação ao cultivo de mudas no verão respectivamente de $94,52 \%$ e $68,38 \%$. Esses dados concordam com os relatados por Silva (1998), 
que observou aumento da porcentagem de estacas de alecrim enraizadas quando tratadas com boro + AIB no inverno.

A presença de folhas pode ter contribuído para o sucesso do enraizamento do alecrim, já que, em recentes estudos de enraizamentos com estacas herbáceas, Morales (1990) ressaltou que, em muitas espécies não é necessário nenhum estímulo ao enraizamento, no entanto em outras, a formação de raizes é dependente das folhas, verificando que o estímulo é necessário e proveniente das mesmas. Fachinello et al. (1994) mencionaram que, a formação das raizes deve-se à interação de fatores existentes nos tecidos da estaca, com substâncias produzidas e translocadas das folhas e gemas.

Além disso, folhas jovens são responsáveis pela produção das auxinas encontradas naturalmente na planta, assim como pela sintese de vitaminas, especialmente B6 (piridoxina), precursora do ANA (ácido naftalenoacético) (Devlin, 1975; Wareing et al., 1981).

Tabela 3. Médias dos parâmetros para o alecrim (Rosmarinus officinalis L.) para qualidade do enraizamento (QE), peso de massa verde da raiz (PVR) avaliados para os dois tipos de estacas

\begin{tabular}{lrr}
\hline TIPO DE ESTACA & QE & PVR $^{*}(\mathbf{g})$ \\
\hline Apical & $2,6666 \mathrm{a}$ & $0,4312 \mathrm{a}$ \\
Não Apical & $0,9166 \mathrm{~b}$ & $0,1397 \mathrm{~b}$ \\
C.V. & $34,21 \%$ & $34,97 \%$ \\
\hline Médias seguidas pelas mesmas letras minúsculas, nas colunas, não diferem estatisticamente \\
entre si, pelo teste de Tukey-kramer, ao nivel de $5 \%$ de significância. \\
"Dados transformados $\log _{10}$ PVR.
\end{tabular}

Tanto para qualidade de enraizamento $(\mathrm{QE})$, como para o peso verde da raiz (PVR), o incremento foi para o tratamento estaca do tipo apical como pode ser visto na Tabela 3. Estes resultados concordam com os apresentados por Marini (1983), onde estacas de pessegueiro retiradas de ápice de ramos enraizaram em maior percentagem do que aquelas retiradas de porções basais. No entanto, Couvillon (1988) afirmou que a posição apical por ser menos 
madura do que a área basal pode causar essa resposta diferenciada em relação à maturidade em detrimento da posição do ramo.

Para peso verde de raiz (PVR) não houve diferença estatística significativa (Tabela 4) quando comparado os sistemas de cultivo. Porém, pode se afirmar que no sistema "floating" a média foi superior $92 \%$ com relação ao sistema areia.

Tabela 4. Peso de massa verde da raiz (PVR) do alecrim (Rosmarinus officinalis L.) avaliados para os sistemas de cultivo

\begin{tabular}{lr}
\hline SISTEMA DE CULTIVO & PVR' (g) \\
\hline Convencional & 0,0555 a \\
Areia & 0,0102 a \\
Floating & 0,1418 a \\
C.V. & $34,97 \%$ \\
\hline Médias seguidas pelas mesmas letras minúsculas, nas colunas, não diferem estatisticamente \\
entre si, pelo teste de Tukey-kramer, ao nivel de 5\% de significância. \\
"Dados transformados log ${ }_{10} P V R$.
\end{tabular}

Esses dados permitem afirmar que o alecrim propagado por estacas herbáceas apicais no inverno no sistema "floating", produz mudas de excelente qualidade para o cultivo.

Não foram observadas diferenças significativas para percentagem de pegamentos de mudas no campo, sendo que todos os tratamentos apresentaram $100 \%$ de pegamento, independente da época do ano.

\subsection{Avaliação da produção de muda do Bálsamo}

$\mathrm{Na}$ Tabela 5 são apresentados os resultados das avaliações para os sistemas de cultivo.

Para peso verde da raiz (PVR), a areia apresentou o melhor resultado quando comparado com os demais sistemas de cultivo, resultado que difere daquele constatado por Long (1932). Isto provavelmente deve-se a baixa tolerância do bálsamo ao excesso de umidade. A areia por apresentar maior proporção de espaço poroso, possui maior capacidade de perda água para o 
ambiente, perdendo água mais rápido que os demais sistemas. Isto beneficiou de alguma forma a capacidade rizogénetica desta espécie que é característica de lugares semi-desérticos como afirmou Lorenzi (2001).

Para o parâmetro qualidade de enraizamento (QE), nota-se que o maior desenvolvimento das mudas foi para o tratamento do sistema "floating" (Tabela 5) provavelmente devido a pronta disponibilidade de água às plantas de bálsamo, porém, em detrimento a produção de massa verde da raiz.

Tabela 5. Peso de massa verde da raiz (PVR) e qualidade do enraizamento (QE) do bálsamo (Sedum dendroideum subsp. praealtum (DC.) R.T. Clausen) avaliados para os sistemas de cultivo no inverno.

\begin{tabular}{lrr}
\hline SISTEMA & PVR $^{*}(\mathbf{g})$ & QE \\
\hline Convencional & $0,8360 \mathrm{~b}$ & $2,2500 \mathrm{~b}$ \\
Areia & $1,3821 \mathrm{a}$ & $1,5000 \mathrm{~b}$ \\
Floating & $0,5768 \mathrm{C}$ & $3,2500 \mathrm{a}$ \\
C.V. & $12,19 \%$ & $22,58 \%$ \\
\hline
\end{tabular}

Médias seguidas pelas mesmas letras minúsculas, nas colunas, não diferem estatisticamente entre si, pelo teste de Duncan, ao nivel de $5 \%$ de significância.

${ }^{*}$ Dados transformados (PVR) ${ }^{-0.5}$.

Não foram observadas diferenças significativas para percentagem de pegamentos de mudas no campo, sendo que todos os tratamentos apresentaram $100 \%$ de pegamento, independente da época do ano.

\subsection{Avaliação da produção de muda da Carqueja}

Nas Tabelas de 6 a 10 são apresentados os resultados das avaliações para a carqueja revelando que a época do ano, o tipo de estaca e o sistema de cultivo, foram estatisticamente significativos para os parâmetros estudados. 
Tabela 6. Peso de massa verde da parte aérea (PVPA) e peso de massa seca da parte aérea (PSPA), da carqueja (Baccharis trimera (Less.) D.C.) avaliados para os sistemas de cultivo no inverno

\begin{tabular}{lrr}
\hline SISTEMA & PVPA (g) & PSPA (g) \\
\hline Convencional & $12,4225 \mathrm{a}$ & $4,6825 \mathrm{a}$ \\
Areia & $7,8262 \mathrm{~b}$ & $3,2425 \mathrm{bc}$ \\
Floating & $12,1325 \mathrm{a}$ & $3,1475 \mathrm{C}$ \\
C.V. & $17,49 \%$ & $13,82 \%$ \\
\hline Médias seguidas pelas mesmas letras minúsculas, nas colunas, não diferem estatisticamente \\
entre si, pelo teste de Tukey, ao nivel de 5\% de significância.
\end{tabular}

Para peso verde da parte área (PVPA) e peso seco da parte aérea (PSPA), notou-se a superioridade do sistema convencional (Tabela 6) em relação aos outros dois sistemas (mudas formadas na areia e no "floating"), sendo que dentre os três, as menores médias foram observadas no sistema areia para PVPA e no sistema "floating" para PSPA. Estes dados diferem daqueles obtidos por Verdial et al. (1998 e 1999), para as culturas de pimentão e tomate, respectivamente. Considerando os resultados obtidos, o meio pode ter influído negativamente no acúmulo de biomassa verde e seca de parte aérea. A carqueja não apresentou dificuldades de enraizamento nos sistemas testados.

Tabela 7. Qualidade do enraizamento (QE) da carqueja (Baccharis trimera (Less.) D.C.) avaliadas sob o tipo da estaca no inverno

\begin{tabular}{lr}
\hline TIPO DE ESTACA & QE \\
\hline Apical & $2,5885 \mathrm{a}$ \\
Não Apical & $2,1614 \mathrm{~b}$ \\
C.V. & $10,77 \%$ \\
\hline Médias seguidas pelas mesmas letras minúsculas, nas colunas, não diferem estatisticamente \\
entre si, pelo teste de Tukey, ao nivel de 5\% de significância.
\end{tabular}

Para qualidade de enraizamento (Tabela 7), a estaca apical apresentou a maior média estatística significativa quando comparada com a não apical, avaliadas na época do inverno, resultado que está em acordo com aqueles obtidos por Pereira et al. (1983). 
Tabela 8. Médias da interação sistema x tipo de estaca, avaliadas para peso de massa verde de raiz (PVR) ${ }^{*}$ nas mudas de carqueja (Baccharis trimera (Less.) D.C.)

\begin{tabular}{lrr}
\hline SISTEMAITIPO DE & APICAL & NÃO APICAL \\
ESTACA & $1,0235 \mathrm{bc} \mathrm{A}$ & $1,0143 \mathrm{bc} \mathrm{A}$ \\
\hline Convencional & $0,9952 \mathrm{c} \mathrm{A}$ & $1,0067 \mathrm{c} \mathrm{A}$ \\
Areia & $1,1357 \mathrm{a} \mathrm{A}$ & $1,0647 \mathrm{a} \mathrm{B}$ \\
Floating & $1,86 \%$ & \\
C.V. & & \\
\hline
\end{tabular}

Médias de sistemas de mesma letra minúscula (na coluna) e média de tipo de estaca seguidas de mesma letra maiúscula (linha) não diferem entre si, pelo teste de Tukey, ao nivel de $5 \%$ de significância.

*Dados transformados (PVR) ${ }^{0,1}$.

A análise de variância para o peso verde de raiz, revelou (Tabela 8) que a interação entre sistema $x$ tipo de estaca foi significativa, demonstrando que 0 sistema "floating" obteve maiores incrementos com ambos os tipos de estacas. Entretanto, a interação mostrou que a estaca apical no sistema "floating" obteve maior acúmulo de biomassa verde de raiz do que a estaca do tipo não apical. Provavelmente, isto é devido ser esta a região de síntese de auxina, conforme os resultados obtidos por Zancan (1989) e Jawanda et al. (1990).

Tabela 9. Peso de massa verde da parte aérea (PVPA) e qualidade de enraizamento (QE) da carqueja (Baccharis trimera (Less.) D.C.) avaliadas no verão e no inverno

\begin{tabular}{lrr}
\hline TIPO DE ESTACA & PVPA $^{*}(\mathbf{g})$ & QE \\
\hline Verão & $1,0719 \mathrm{a}$ & $1,8250 \mathrm{~b}$ \\
Inverno & $0,3426 \mathrm{~b}$ & $2,6640 \mathrm{a}$ \\
C.V. & $20,65 \%$ & $17,62 \%$ \\
\hline
\end{tabular}

Médias seguidas pelas mesmas letras minúsculas, nas colunas, não diferem estatisticamente entre si, pelo teste de Tukey, ao nivel de $5 \%$ de significância.

*Dados transformados $\log _{10}$ PVPA.

Para peso verde de parte aérea (PVPA) como pode ser visto na Tabela 9, a melhor época para acúmulo de biomassa fresca é no verão. Este resultado está de acordo com a pesquisa de Souza (1998), que trabalhando com tanchagem (Plantago major L.) sob alta intensidade luminosa, obteve efeito significativo na produção de biomassa fresca e verde de folhas. 
Tabela 10. Médias da interação sistema x época do ano, avaliadas para peso de massa verde de raiz (PVR) nas mudas de carqueja (Baccharis trimera (Less.) D.C.)

\begin{tabular}{lrr}
\hline SISTEMAI ÉPOCA & VERÃO & INVERNO \\
\hline Convencional & 0,1802 a A & 0,1006 b B \\
Areia & - & \\
Floating & 0,2348 a B & 0,5524 a A \\
C.V. & $27,82 \%$ & \\
\hline
\end{tabular}

Médias de sistemas de mesma letra minúscula (na coluna) e média de tipo de estaca seguidas de mesma letra maiúscula (linha) não diferem entre si, pelo teste de Tukey, ao nivel de $5 \%$ de significância.

*Dados transformados $\log _{10} P V R$

Para a interação entre sistema e época do ano considerando o peso verde de raiz conforme mostra a Tabela 10 , pode-se observar que em ambas épocas do ano, a carqueja no sistema areia não se desenvolveu bem. Contudo, no verão não houve diferença estatística para os outros dois sistemas, sendo diferente no inverno quando o sistema "floating" destacou-se apresentando a maior média estatisticamente significativa.

$\mathrm{Na}$ interação entre as épocas, a carqueja demonstrou possuir a capacidade de enraizar nas diferentes épocas testadas, porém, os melhores resultados foram obtidos no inverno no sistema "floating" para estacas apicais, resultados esses que concordam com os apresentados por Evans (1973).

Não foram observadas diferenças significativas para percentagem de pegamentos de mudas no campo, sendo que todos os tratamentos apresentaram $100 \%$ de pegamento, independente da época do ano. 


\subsection{Avaliação da produção de muda do Tomilho}

$\mathrm{Na}$ Tabela 11 são apresentados os resultados das avaliações para o sistema de cultivo do tomilho, que apresentou diferenças estatisticamente significativas para os parâmetros estudados.

Para os parâmetros peso de massa verde da parte aérea (PVPA); peso de massa seca da parte aérea (PSPA), peso de massa verde da raiz (PVR), e peso de massa seca da raiz (PSR), avaliados para os três sistemas de cultivo as maiores médias foram obtidas no sistema convencional em relação a areia, pois no sistema 'floating", todas as estacas morreram, tanto as estacas apicais quanto as não apicais. Provavelmente a morte das estacas está associada ao excesso de umidade presente neste sistema, uma vez que de acordo com Corrêa Jr et al. (1994) a umidade é um fator limitante para esta espécie.

Tabela 11. Peso de massa verde da parte aérea (PVPA); peso de massa seca da parte aérea (PSPA), peso de massa verde da raiz (PVR), e peso de massa seca da raiz (PSR) do tomilho (Thymus vulgaris L.) avaliados para os sistemas de cultivo na época do inverno

\begin{tabular}{lcccr}
\hline SISTEMA & PVPA $(\mathbf{g})$ & PSPA $(\mathbf{g})$ & PVR $(\mathbf{g})$ & PSR $(\mathbf{g})$ \\
\hline Convencional & $4,7000 \mathrm{a}$ & $1,2400 \mathrm{a}$ & $3,8375 \mathrm{a}$ & $0,4975 \mathrm{a}$ \\
Areia & $3,0375 \mathrm{~b}$ & $0,8550 \mathrm{~b}$ & $2,0250 \mathrm{~b}$ & $0,2500 \mathrm{~b}$ \\
Floating & - & - & - & - \\
C.V. & $18,75 \%$ & $20,96 \%$ & $25,05 \%$ & $23,79 \%$ \\
\hline $\begin{array}{l}\text { Médias seguidas pelas mesmas letras minúsculas, nas colunas, não diferem estatisticamente } \\
\text { entre si, pelo teste de Duncan, ao nivel de } 5 \% \text { de significância. }\end{array}$
\end{tabular}

Não foram observadas diferenças significativas para percentagem de pegamentos de mudas no campo, sendo que todos os tratamentos apresentaram $100 \%$ de pegamento, independente da época do ano. 


\section{CONCLUSÕES}

- As mudas formadas pelas estacas apicais de alecrim, carqueja e tomilho apresentaram as maiores médias para os parâmetros estudados.

A utilização do sistema "floating" no desenvolvimento de mudas de carqueja formadas por estacas apicais no verão apresentaram ser viável, permitindo o controle do desenvolvimento das mesmas e proporcionando melhores índices de pegamento em campo.

Plantas de bálsamo produzem mudas de alta qualidade no inverno, quando plantadas no sistema de areia.

As maiores produções de mudas de tomilho foram obtidas no inverno utilizando o sistema convencional. 


\section{REFERÊNCIAS BIBLIOGRÁFICAS}

ALBUQUERQUE, J.M.D. Plantas medicinais de uso popular. Brasilia: ABEAS, 1989.96p. (Programa Agricultura nos Trópicos).

ALVARENGA, L. R. de; CARVALHO, V.D. de. Uso de substâncias promotoras de enraizamento de estacas frutíferas. Informe Agropecuário, v.9, n.101, p.47-55, maio 1983.

BALBACH, A. As plantas curam. 3.ed. São Paulo: Editora Missionária, s.d. $472 p$.

BANZATTO, A.D.; KRONKA, N.S. Experimentação agrícola. Jaboticabal: FUNEP, 1989. 247p.

BARROSO, G.M. Compositae - subtribo BACCHARIDINEAE Hoffmann estudo das espécies ocorrentes no Brasil. Campinas: UNICAMP, 1973. $281 p$.

BARROSO, G.M. Sistemática de angiospermas do Brasil. Viçosa: Imprensa Universitária da UFV, 1991. v.3, 326p. 
BECKER, L. Propagação vegetativa in vivo de Phyllanthus corcovadensis Muell. Arg. $E$ in vitro, indução de calos, nutrição, extração e quantificação de alcalóides na espécie Phyllanthus niruri L. (quebra-pedras). Lavras, 1997. 96p. Dissertação (Mestrado) - Universidade Federal de Viçosa.

BLAZICH, F.A. Chemicals and formulations used to promote adventitious rooting. In: DAVIS, T.D.; HAISSIG, B.E.; SANKHALA, N. Advances in plant sciences: adventitious root formation in cuttings. Oregon: Dioscorides Press, 1988. v.2, p.132-149.

BLISKA JUNIOR, A.; HONÓRIO, S.L. Cartilha tecnológica: plasticultura e casa de vegetação. Campinas: FEAGRI, 1996. 85p.

BORELLA, J.C.; FONTOURA, A.; MENEZES, JUNIOR, A.; FRANÇA, S.C. Influência da adubação mineral (N-P-K) e sazonalidade no rendimento e teor de flavonóides em indivíduos masculinos de Baccharis trimera Less. (Asteraceae) - Carqueja. Revista Brasileira de Plantas Medicinais, v.4, n.1, p.101-104, 2001.

BORNE, H.R. Produção de hortaliças. Guaíba: Agropecuária, 1999. 189p.

CALIXTO, J.B. Medicamentos fitoterápicos. In: YUNES, R.A.; CALIXTO, J.B. Plantas medicinais sob a ótica da química medicinal moderna. Chapecó: Argos, 2001. p. 298-315. 
CAMPELO, C.R. Contribuição ao estudo das plantas medicinais no Estado de Alagoas. Acta Amazônica, v.18, n.1/2, p.305-312, 1988.

CARDAMONE, R.B. No jardim das plantas medicinais. Campinas: Editora R. B. Cardamone, 1999. 110 p.

CARMO JUNIOR, R.R. Produção de alface (Lactuca sativa L.) em cultivo hidropônico utilizando atmosfera modificada no interior de casa de vegetação. Campinas, 2000. 96p. Dissertação (Mestrado) - Universidade de Campinas.

CARRIJO, E.P.;.GONTIJO, T.C.A.; PIO, R.; COELHO, J.H.C.; CHALFUN, N.N.J.; RAMOS, J.D.; Propagação de estacas do porta-enxerto de pereira Pyrus calleryana Dene. In: CONGRESSO DE INICIAÇÃO CIENTIFÍCA DA UNIVERSIDADE FEDERAL DE LAVRAS, 15, Lavras, 2002. Anais. Lavras: UFLA, 2002.p.39.

CASTLE, W.S.; ROUSE, R.E. Total mineral content of Florida Citrus nurseries plants. Proceedings of the Florida State For Horticultural Society, v.103, p.42-44, 1991.

CASTRO, H.G. Estudo anatômico da carqueja (Baccharis myriocephala). Viçosa: Universidade Federal de Viçosa, 1996. 21p. 
CASTRO, N.E.A. Época de plantio e método de colheita para maximização da produção de cálices de Hibiscus sabdariffa L. Lavras, 2003. 62p. Dissertação (Mestrado) - Universidade Federal de Lavras.

CERRI, C. Ervas: receita de bons lucros. Globo Rural, n.121, p.42-51, 1995.

CHAUHAN, K,S; MAHESHWARI, L.D. Effect of certain plant growth regulators, seasons and types of cutting on root initiation and vegetative growth in stem cuttings peach variety "Sharbati". Indian Journal of Horticulture, v.27, n.3/4, p.136-140, 1970.

CHEN, Q.; SHI, H.; HO,C.T. Effects of rosemary extracts and major constituents of lypid oxidation and soybean lipoxygenase activity. Journal of American Oil Chemistry Society, v.69, n.10, p.999-1002, 1992.

CLEMENTE FILHA, A.C. Aspectos fisiológicos e fitoquímicos de Bauhinia forticata Link e Plantago major L. Lavras, 1996. 67p. Dissertação (Mestrado) - Universidade Feral de Lavras.

CORREAA, A. D.; BATISTA, R.S.; QUINTAS, L.E.M. Plantas medicinais: do cultivo à terapêutica. Petrópolis: Vozes, 1998. 246p.

CORREAA JÚNIOR, C.; MING, L.C.; SCHEFFER, M.C. Cultivo de plantas medicinais, condimentares e aromáticas. Jaboticabal: FUNEP, 1994. $162 p$. 
COUVILLON, G.A. Rooting response to different treatments. Acta Horticulturae, n.227, p.187-196. 1988

CRONQUIST, A. An integrated system of classification of sister to the clade consisting of three orders: malvales, flowering plants. New York: Columbia University Press, 1981. $681 \mathrm{p}$.

DESCHAMPS, C. Propagação vegetativa "in vivo"e "in vitro" de sarandi (Sebastiania schottiana Muell. Arg.), espécie florestal de mata ciliar. Lavras: 1993. 128p. Dissertação (Mestrado) - Escola Superior de Agricultura de Lavras.

DEVLIN, R.M. Plant physiology. New York: Van Nostrand Reinhold, 1975. $606 p$.

DI STASI, L.C. Plantas medicinais: arte e ciência. Um guia de estudo interdisciplinar. São Paulo: Fundação Unesp, 1996, 230 p.

DIAS, M.C.; CAMARGO, R. Estudos da adubação e propagação de carqueja. In: WORKSHOP DE PLANTAS MEDICINAIS DE BOTUCATU, 2., Botucatu, 1996. Anais. Botucatu: UNESP, 1996. p.69.

ELISABETSKY, E. Etnofarmacologia de algumas tribos brasileiras. In: RIBEIRO, D. (Ed.). Suma etnológica brasileira. Petrópolis: FINEP, 1986. v. 1, p. $135-150$. 
ERVAS E TEMPEROS. Guia rural. São Paulo: Editora Abril, s.d. v.1, p.12-135.

EVANS, L.T. The effect of light on plant development and yield. In: SLATYER, R.O. (Ed.). Plant responses to climatic factors. Paris: UNESCO, 1973. p. 21-35.

FACHINELLO, J.C.; HOFFMANN,A.; NACHTIGAL, J.C.; KERSTEN, E.; FORTES, G.R. L. Propagação de plantas frutíferas de clima temperado. 2. ed. Pelotas: UFPEL, 1994. 179p.

FARAG, R.S.; BADEI, A.Z.M.A.; HEWEDI, F.M.; EL BAROTY, G.S.A. Antioxidant activity of skome??? spice essencial oils on linoleic acid oxidation in aqueais media. Journal of American Oil Chemistry Society, v.66, n.6, p.792-799, 1989.

FERNANDES, P.C.; FACANALI, R.; TEIXEIRA, J.P.F.; FURLANI, P.R.; MARQUES, M.O.M. Cultivo de manjericão em hidroponia e em diferentes substratos sob ambiente protegido. Horticultura Brasileira, v.22, n.2, p.260-264, abr./Jun, 2004.

FIDELIS, I. Propagação de Brosimum guadichaudii Tréc. (Man Cadela) uma espécie considerada medicinal. Lavras 1998. 109p. Dissertação (Mestrado) - Universidade Federal de Lavras.

FIGUEIREDO, N. Rezadores, pajés \& puçangas. Belém: Boitempo, 1979. 96p. 
FURLAN, M.R. Aspectos agronômicos em plantas medicinais. In: DI STASI, L.C. Plantas medicinais: arte e ciência. Um guia de estudo interdisciplinar. São Paulo: Fundação Unesp, 1996. p.157-167.

GIACOMETTI, D.C. Ervas condimentares e especiarias. São Paulo: Nobel, 1989. 158p.

GLÓRIA, B.A. da. Estruturas secretoras nos vegetais superiores. Piracicaba: ESALQ, 1995. 13p.

HAISSIG, B.E. Metabolic process in adventitious rooting of cuttings. In: JACKSON, M.B. New root formation in plants and cuttings. Dordrecht: Martinus Nijhoff, 1986. p.141-189.

HARTMANN, H.T.; KESTER, D.E.: Plant propagation: principles and practices. 4. ed. New York: Prentice Hall, 1983. 727p.

HARTMANN, H.T.; KESTER, D.E.; DAVIES JÚNIOR, F.T. Plant propagation: principles and practices. 5. ed. New York: Prentice Hall, 1990. 647p.

HIDALGO, L. Tratado de viticultura general. Madrid: Mundi-Prensa, 1993. $983 p$. 
HORNER, M.C.; PEIL, R.M., FERREIRA, A.F.; STRASSBURGER, A.S.; NICOLLETI, D.R. Avaliação do crescimento de mudas para o cultivo sem solo do tomateiro em diferentes substratos. Horticultura Brasileira, v.21, n.2, p.280, 2003. Supl. 1.

INSTITUTO AGRONÔMICO DO PARANÁ. Plantas medicinais. Londrina, 1994. 1v.

JANICK, J. A ciência da horticultura. Rio de Janeiro: Livraria Freitas Bastos, 1966. p.202-237: Orientação do crescimento da planta.

JANICK, J. A ciência da horticultura. Rio de Janeiro: Freitas Bastos, 1968. $485 p$.

JAKUPOVIC, J.; SCHUSTER, A.; GANZER, U.; BOHLMANN, F.; BOLDT, P.E. Sequi- and diterpenes from Baccharis species. Phytochemistry, v.29, n.7, p.2217-2222, July 1990 .

JAWANDA, J.S.; SINGH, A.; SINGH, S.; BAL, J.S. Effect of indolbutyric acid and shoot portion on the rooting of cuttings in Japanese plum. Acta Horticulturae, n.283, p.189-197, 1990.

KRAMER, J.P.; KOZLOWSKI, T. Fisiologia das árvores. Lisboa: Fundação Calonste Gulbenkian, 1972. 745p. 
LEAL, T.C.A.B.; SILVA, J.F. Plantas medicinais e aromáticas: generalidades, informações sobre cultivo e descrição de algumas espécies. Campos de Goytacazes: UENF, 1996.18p.

LIMA, N.G.; HAMERSCHIMIDT, J. As culturas de alface e tomate em estufas. Horticultura Brasileira, v.4, n.1, p.44, 1986.

LOAYZA, I.; ABUJDER, D.; ARANDA, R.; JAKUPOVIC, J.; COLLIN, G.; DESLAURIERS, H.; JEAN, F.I. Essencial oils of Baccharis salicifolia, $B$. latifolia, and B. dracunculifolia. Phytochemistry, v.38, n.2, p.381-389, Feb. 1995.

LONG, J.C. The influence of rooting media on the character of roots produced by cuttings. Proceedings of the American State for Horticultural Science, v.29, p.352-355, 1932.

LORENZI, H. Plantas ornamentais no Brasil: arbustivas, herbáceas e trepadeiras. Nova Odessa: Instituto Plantarum, 2001. 476p.

LORENZI, H.; MATOS, F.J.A. Plantas medicinais no Brasil: nativas e exóticas cultivadas. Nova Odessa: Instituto Plantarum, 2002.512p.

LOVELL, P.H.; WHITE, J. Anatomical changes during adventitious root formation. In: JACKSON, M.B. New root formation in plants and cuttings. Dordrecht: Martinus Nijhoff, 1986. p.111-140. 
MAGALHÃES, P.M. O caminho medicinal das plantas: aspectos sobre o cultivo. Campinas: UNICAMP; CPQBA, 1997. 117p.

MAHLSTEDE, J.P.; HABER, E.S. Plant propagation. New York: John Wiley, $1957.413 p$.

MARANCA, G. Plantas aromáticas na alimentação. São Paulo: Nobel, 1986. $123 \mathrm{p}$.

MARINI, R.P. Rooting of semihardwood peach cutting as affected by shoot position and thickeness. HortScience, v.18, n.5, p.718-719, 1983.

MARTINS, E.R. Morfologia interna e externa, caracterização isozimática e óleo essencial de Ocimum selloi Benth. Viçosa: 1996. 97p. Dissertação (Mestrado) - Universidade Federal de Viçosa.

MARTINS, E.R.; CASTRO, D.M.; CASTELLANI, D.C.; DIAS, J.R. Plantas medicinais. Viçosa: UFV, 1995. 220p.

MARTINS, E.R.; CASTRO, D.M.; CASTELLANI, D.C.; DIAS, J.R. Plantas medicinais. Viçosa: UFV, 2000. 220p.

MEHROTRA, N.K.; SING, H. Effects of type of cutting and seradix-b on the rooting and plant growth of plum $\mathrm{cv}$. Kala Amritsri. Indian Journal of Horticulturae, v.48, n.2, p.124-126, June 1991. 
MENDONÇA, M.C.S. Efeito do ácido indolbutírico no enraizamento de estacas de alecrim-pimenta (Lippia sidoides Cham.). Fortaleza: 1997. 43p. Dissertação (Mestrado) - Universidade Federal do Ceará.

MINAMI, K.; TESSARIOLI NETO, J.; PENTEADO, S. R.; SCARPARI FILHO, J.A. Produção de mudas hortícolas de alta qualidade. Piracicaba: ESALQ; SEBRAE, 1994. 155p.

MING, L.C. Influência da adubação orgânica na produção de biomassa e teor de óleos essenciais de Lippia alba. Horticultura Brasileira, v.2, n.1, p.49$52,1994$.

MING, L.C. Produção e comercialização de plantas medicinais e aromáticas no Brasil. In: CONGRESSO BRASILEIRO DE OLERICULTURA, 35, Foz do Iguaçu, 1995. Anais. Curitiba: Sociedade Brasileira de Olericultura, 1995. p.118-119.

MITCHELL, J.W.; MERTH, P.C. Fitohormonas y otros reguladores de crescimiento para huertas, campos, jardines y cosechas. Madrid: Ediciones Aguilar, 1950. 151p.

MOL, D.J.S.; SILVA, F.G.; PINTO, CARDOSO, M.G.; NASCIMENTO, V.E.; BERTOLUCCI, S.K.V. Avaliação da emissão de brotação pós-colheita e rendimento de óleo essencial em carqueja em função do número e altura de cortes. Horticultura Brasileira, v.21,n.2, p.410, jul. 2003. Supl. 1. 
MORALES, G.C.F. Influência do AIB e da presença de folhas no enraizamento de estacas de laranjeira "Valência" e tangerinas "Montenegrinas". Porto Alegre: 1990. Dissertação (Mestrado) - Universidade Federal do Rio Grande do Sul.

MOREIRA, F. As plantas que cura cuide da sua saúde através da natureza. São Paulo: Hemus Livraria, 2002. 256p.

MORGAN, R. Enciclopédia das ervas e plantas medicinais. São Paulo: Hemus Livraria, 1994. 555p.

MYRE, A.S.; SCHWARTZE, C.D. Rooting evergreen cuttings with hormone. Proceedings of the American Society of Horticultural Science, v.21, p.639-650, 1948.

MUÑOZ, F. L.B. Plantas medicinales y aromaticas: estudio, cultivo y procesado. Madrid: Mundi-Prensa, 2000.365p.

NEITZKE, R.S.; LUDWIG, F.; MORSELLI, T.B.G.A. Produção de mudas de petúnia (Petúnia hybrida) em diferentes vermicompostos. Horticultura Brasileira. v.21, n.2, p.270, jul.2003. Supl. 1.

OLIVEIRA, F.G. Avaliação de métodos de estimativa da evapotranspiração do feijoeiro (Phaseolus vulgaris L.) irrigado por aspersão do tipo pivô central. Viçosa: 1996. 71p. Dissertação (Mestrado) - Universidade Federal de Viçosa. 
OLIVEIRA, F.de. Farmacognosia. São Paulo: ed. Atheneu, 1998. 178p.

PASQUAL, M.; CHALFUN, N.N.J.; RAMOS, J.D.; VALE, M.R. do; SILVA, C.R. de R. E. Fruticultura comercial: propagação de plantas frutiferas. Lavras: UFLA; FAEPE, 2001. 137p.

PASQUALETTO, A. Influência de reguladores de crescimento e de sacarose no enraizamento de estacas de soja (Glycine max. (L.) Merrill). Viçosa, 1995. 98p. Dissertação (Mestrado) - Universidade Federal de Viçosa.

PEARCE, S.E.M. In manipulating secondary metabolism in culture. In: ROBINS, R.J.; RHODES, M.J.C. Secundary products from plant tissue culture. Cambridge: University Press, 1988, p.155.

PEREIRA, F.M.; OIOLI, A.A.P.; BANZATO, D.A. Enraizamento de diferentes tipos de estacas enfolhadas de goiabeira (Psidium guajava L.) em câmara de nebulização. Científica, v.11, n.2, p.239-244, 1983.

PINTO, J.P. Efeito de tipos de coberturas de polietileno preto na evapotranspiração e na produção da cultura de alface. Viçosa, 1997. 55p. Dissertação (Mestrado) - Universidade Federal de Viçosa.

PLATT, R.G.; OPITZ, K. Propagation of citrus. In: REUTHER, W. The citrus industry. Berkeley: University of California, 1973. v.3, p.1-47. 
POKORNY, F.A.; AUSTIN, M.E. Propagation of blueberry by softwood terminal cuttings in pine bark and peat media. HortScience, v.17, p.640-642, 1982.

QUEIROGA, M.L.; FERRACINE, V.; MARSAIOLI, A.J. Three new oxigenated cadinanes from Baccharis species. Phytochemistry, v.42, n.4, p.10971103, Apr.1996.

REGINA, M. A.; SOUZA, C. R. de; SILVA, T. G.; PEREIRA, A.F. A propagação da videira. Informe Agropecuário, v.19, n.194, p.20-27, 1988.

RESH, H.M. Hydroponic food production: a definitive guidebook for the advanced home gardener and the commercial hydroponic grower. Santa Barbara: Woodbridge Press Publishing, 1997. 527p.

RODRIGUES, E.R. PEDRAZZI, A.H.P., ZANARDO, A.; FRANCO, J.J. Toxicologia pré-clínica da carqueja. In: SIMPÓSIO DE PLANTAS MEDICINAIS DO BRASIL, 13., Fortaleza, 1994. Resumos. Fortaleza: UFC, 1994.

SÁ, M.F.A. Estudo anatômico e ensaios fitoquímicos de Baccharis myriocephala D.L. carqueja. Rio de Janeiro, 1992. 91p. Dissertação (Mestrado) Universidade Federal do Rio de Janeiro. 
SALOMÃO, L.C.C.; PEREIRA, W.E.; DUARTE, R.C.; SIQUEIRA, D.L. de. Propagação por estaquia dos maracujazeiros doce (Passiflora alata Dryand.) e amarelo (Passiflora edulis f. flavicarpa Deg.). Revista Brasileira de Fruticultura, v.24, n.1, p.163-167, abr.2002.

SCHEFFER, M.C. Estudo de aspectos agronômicos das plantas medicinais selecionadas pela fitorerapia do SUS - PR/ CEMEPAR. Informa, v.10, p.2931, 1991.

SERAFINI, L.A.; CASSEL, E. Produção de óleos essenciais: uma alternativa para a agroindústria nacional. In: SERAFINI, L.A.; BARROS, N.M.; AZEVEDO, J.L. Biotecnologia na agricultura e na agroindustria. Guaiba: Agropecuária, 2001. cap.9., p.333-355.

SERTIÉ, J. CEME avalia uso de plantas como medicamentos. O Estado de São Paulo, São Paulo, 2 fev.1997.p.a23.

SILVA, A. F. Crescimento e teores de nutriente em alface, salsa e cebolinha influenciados por $\mathrm{CaCO}_{3}$ e pela correção de $\mathrm{pH}$ da solução hidropônica. Viçosa, 1999.70p. Dissertação (Mestrado) - Universidade Federal de Viçosa.

SILVA, C P. Efeitos das interações entre auxinas, ácido bórico e época de coleta, no enraizamento de estacas herbáceas de alecrim (Rosmarinus officinalis L.) In: MING, L.C.Plantas medicinais aromáticas e condimentares: avanços na pesquisa agronômica, Botucatu: UNESP, 1998. v. 2, p. $155-168$. 
SILVA, J.B.; GROTTA, A. S. Anatomia e óleo essencial de Baccaris retusa D.C. Revista de Farmácia e Bioquímica da Universidade de São Paulo, v.9, n.2, p.321-326, 1971.

SIMÃO, S. Manual de fruticutura. 7.ed. São Paulo: Agronômica Ceres, 1971. $530 \mathrm{p}$.

SOUZA, M.M. Crescimento e metabolismo secundário em duas condições de luminosidade e cultura in vitro de Plantago major L. Viçosa, 1998. 106p. Tese (Doutorado) - Universidade Federal de Viçosa.

SOUZA, M.P.; OLIVEIRA MATOS, M.E.; ABREU MATOS, F.J. Constituintes químicos ativos de plantas medicinais brasileiras. Fortaleza: UFC, Laboratório de Produtos Naturais, 1991. $416 p$.

SUTTISRI, R.; KINGHORN, A.D.; WRIGHT, A. D.; STICHER, O. Neoclerodane diterpenoids and other constituents from Baccharis genistelloides. Phytochemistry, v.35, n.2, p.443-446, Feb. 1994.

TESSARIOLI NETO, J. Recipientes, embalagens e acondicionamentos de mudas de hortaliças. In: MINAMI, K. Produção de mudas de alta qualidade em horticultura. São Paulo: T.A. QUEIROZ, 1995. cap.4., p.5964. 
TETENYI, P. Biological precoditions fo cultivation and procescinal of medicinal plants. In: WIJESEKERA, R.O.B. The medicinal plant industry. Boca Raton: CRC Press, 1991. cap.3, p.33-41.

TORRES, A.C.; CALDAS, L.S. Técnicas e aplicações da cultura de tecidos de plantas. Brasilia: ABCTP; EMBRAPA, CNPH, 1990. 433p.

TORREY, J.G. Endogenous and exogenous influences on the regulation of lateral root formation. In: JACKSON, M.B. (Ed.). New root formation in plants and cuttings. Dordrecht: Matinus Nijhoff, 1996. p.31-66.

VERDIAL, M.F.; IWATA, A.Y.; LIMA, M.S. de; TESSARIOLI NETO, J. Influência do "floating" no condicionamento e crescimento de mudas de pimentão (Capsicum annum L.) Scientia Agricola, v.55, p.25-28, 1998.

VERDIAL, M.F.; IWATA, A.Y.; LIMA, M.S. de; TESSARIOLI NETO, J.; TAVARES, M. Influência do sistema de "floating" no condicionamento do crescimento mudas de tomateiro (Lycopersicon esculentum Mill.). Revista de Agricultura, v.74, p.107-115, 1999.

VERDIAL, M.F.; LIMA, M.S. de; TESSARIOLI NETO, J. DIAS, C.T.S.; BARBANO, M.T. Métodos de formação de mudas de maracujazeiro amarelo. Scientia Agricola, v.57, n.4, p.795-798, 2000.

VIEIRA, L.S. Fitoterapia da Amazônia. 2.ed. São Paulo: Ceres, 1992. 347p. 
VON HERTWIG, I.F. Plantas aromáticas e medicinais. São Paulo: Ícone, 1986. 450p.

YUNES, R.A.; CALIXTO, J.B. Plantas medicinais sob a ótica da química medicinal moderna. Chapecó: Argos, 2001. 500p.

WARDLAW, I.F. The control of carbon partitioning in plants. New Phytologist, v.116, p.341-381, 1990.

WAREING, P.F.; PHILLIPS, I.D.J. Growth and differentiation in plants. New York: Perganom Press, 1981. 343p.

WEAVER, R.J. Reguladores del crescimiento en la agriculture. 2.ed. Bracelona: Trillas, 1972. 540p.

WILKINS, M.B. Advanced plant physiology. London: Pitman Press, 1985. $514 p$.

ZANCAN, C. Influência do fatores ambientais, fisiológicos e genéticos no pegamento e desenvolvimento de microenxerto in vitro de ameixeira (Prunus salicina Lindl.). Pelotas, 1989. 92p. Dissertação (Mestrado) Universidade Federal de Pelotas. 